$1-1-2020$

\title{
Drivers and trends in catch of benthic resources in Chilean TURFs and surrounding open access areas
}

Jennifer Beckensteiner

Virginia Institute of Marine Science

Andrew M. Scheld

Virginia Institute of Marine Science

Miriam Fernandez

David M. Kaplan

Virginia Institute of Marine Science

Follow this and additional works at: https://scholarworks.wm.edu/vimsarticles

Part of the Aquaculture and Fisheries Commons

\section{Recommended Citation}

Beckensteiner, Jennifer; Scheld, Andrew M.; Fernandez, Miriam; and Kaplan, David M., Drivers and trends in catch of benthic resources in Chilean TURFs and surrounding open access areas (2020). Ocean \& Coastal Management, 183, 104961.

10.1016/j.ocecoaman.2019.104961

This Article is brought to you for free and open access by the Virginia Institute of Marine Science at W\&M ScholarWorks. It has been accepted for inclusion in VIMS Articles by an authorized administrator of W\&M ScholarWorks. For more information, please contact scholarworks@wm.edu. 
1 Drivers and trends in catch of benthic resources in Chilean TURFs and surrounding Open

2 Access Areas.

3

4 Jennifer Beckensteiner ${ }^{\mathrm{a},{ }^{*}}$, Andrew M. Scheld ${ }^{\mathrm{a}}$, Miriam Fernández ${ }^{\mathrm{b}}$, David M. Kaplan ${ }^{\mathrm{a}, \mathrm{c}}$

5

$6 \quad{ }^{a}$ Department of Fisheries Science, Virginia Institute of Marine Science (VIMS), William \&

7 Mary, Gloucester Point, VA, USA

8 b $\quad$ Núcleo Mileno Centro de Conservación Marina CCM, Estación Costera de Investigaciones

9 Marinas, Departamento de Ecología, Facultad de Ciencias Biológicas, Pontificia Universidad

10 Católica de Chile, Santiago, Chile

11 ' IRD, MARBEC (U. Montpellier, CNRS, Ifremer, IRD), av. Jean Monnet, CS 30171, 34203,

12 Sète cedex, France

13 *Corresponding author (jennifer.beckensteiner@gmail.com)

14

15 https://doi.org/10.1016/j.ocecoaman.2019.104961

16 Received 12 May 2019; Received in revised form 6 September 2019; Accepted 6 September

$17 \quad 2019$

18

19 Abstract

20 Beginning in the 1990's, Chile implemented an extensive Territorial User Rights for Fisheries

21 (TURFs) network that now comprises nearly 1,000 TURFs. This network provides a rare

22 opportunity to examine spatial and temporal trends in TURF use and impacts on surrounding open

23 access areas (OAAs). In this analysis, landings of keyhole limpet (Fissurella spp.), kelp (Lessonia 
24 spp.) and red sea urchin (Loxechinus albus) were used to estimate catch-per-unit effort (CPUEs)

25 and catch-per-unit area (CPUAs) indices inside and outside TURFs by fishing cove. For these

26 species, CPUEs and CPUAs in 2015 were significantly higher inside TURFs. However, temporal

27 trends analyzed with a linear mixed effects model indicate that CPUAs inside TURFs have been

28 significantly decreasing since 2000 for keyhole limpet, red sea urchin and for loco (Concholepas

29 concholepas), while in OAAs this measure only decreased for limpet. An elastic net regression

30 was used to better explain catches in OAAs during 2015, including a variety of variables related

31 to the characteristics and activity of proximal TURFs. Results indicate that exogenous factors

32 unrelated to TURF management were the primary drivers of catches in OAAs during 2015 but that

33 factors related to proximal TURFs appear to have a slight negative impact that grows over time.

34 Collectively, these results indicate that while TURFs are associated with higher catch rates than

35 surrounding OAAs, catch rates appear to be decreasing over time and, though limited, the impact

36 of TURFs on surrounding OAAs may be negative. These findings suggest a need for a more

37 nuanced and dynamic approach to spatial management on benthic resources in Chile.

39 Abbreviations

40 CPUA: Catch per unit of area

41 CPUE: Catch per unit of effort

42 OAA: Open access area

43 TURF: Territorial user right for fisheries 


\section{Introduction}

Spatial property rights can eliminate many common pool externalities that plague fisheries,

47 thereby better incentivizing sustainable and profitable resource use (Beddington et al. 2007, 48 Cancino 2007, Costello et al. 2008). Specifically, Territorial User Rights for Fisheries (TURFs) is a management tool that grants individuals or groups exclusive access to harvest resources within an area (Christy 1982). TURFs have been associated with biological, ecological and economic benefits in several small-scale fisheries (Castilla and Fernández 1998, Gelcich et al. 2008a, 2012, Defeo et al. 2016). During the last decade, TURFs have been promoted as a general approach to tackling the negative impacts of open access fishing (Wilen et al. 2012, Kratz and Block 2013, FAO 2014, Nguyen Thi Quinh et al. 2017), particularly for unassessed fisheries in developing 55 countries that often suffer from overexploitation (Costello et al. 2012). However, the full impacts of TURFs on fisheries sustainability, including long-term trends in catch rates and impacts beyond

57 TURFs boundaries, are not yet fully understood (Orensanz et al. 2005, Aburto and Stotz 2013, Aburto et al. 2014, Gelcich et al. 2019). As the implementation of individual quotas and marine protected areas has been found to have unintended impacts on unregulated subpopulations and habitats (referred to here as “management spillover”; Hilborn et al. 2004, Murawski et al. 2005, Asche et al. 2007, Branch 2009, Abbott and Haynie 2012), similar effects might be expected from

62 other area- or rights-based management and conservation instruments, including TURFs. To our knowledge, the influence of the implementation of TURFs on surrounding areas has not yet been assessed (Nguyen Thi Quinh et al. 2017) despite the fact that the spatial dynamics of most fisheries exceed the scale of an individual TURF. This study looked at the long-term changes in catch and catch rates (i.e., catch per unit effort, CPUEs, and catch per unit area, CPUAs) inside and outside

67 TURF managed areas and also evaluated the possibility of management spillover. 
In Chile, the implementation of TURFs was a reaction to the collapse of the economically important artisanal fishery for the muricid snail Concholepas concholepas in the 1980s (known in Chile as loco, elsewhere as the false abalone) (Bernal et al. 1999). The fast recovery of the high

71 valued loco stocks in initial TURFs increased demand for further TURF development along the

72 entire Chilean coast throughout the 2000s. In 2017, there were 957 officially designated Chilean

73 TURFs implemented as part of a national TURF policy (Fishery and Aquaculture Law $\mathrm{n}^{\circ}$ 18,

74 1991). According to the Chilean Fisheries Authorities, the primary objectives of Chilean TURFs 75 are to "ensure the sustainability of artisanal fishing through the assignment of natural banks", and 76 to "maintain and increase the biological productivity of benthic resources” (SUBPESCA, 2003).

77 This TURF network constitutes the dominant form of spatial management of benthic resources in 78 Chile and is the largest worldwide, covering about $1,500 \mathrm{~km}^{2}$ (though only about half of these 957 79 TURFs are currently operative). Known in Chile as “Área de Manejo y Explotaciones de Recursos 80 Bentónicos” (Management Areas for the Exploitation of Benthic Resources; AMERB), this system 81 grants exclusive fishing rights to legally constituted fishing organizations for the exploitation of 82 benthic resources in defined portions of the seabed - usually adjacent to a caleta or artisanal fishing cove (Aburto et al. 2013). Each TURF has species-specific quotas proposed by the fishing organization and approved by the Undersecretary of Fisheries. Artisanal fisher organizations have 85 to comply with a series of regulations, such as establishing a baseline study, management plan, 86 and regular stock assessments, for which they have to contract technical assistance from 87 specialized environmental and/or fisheries consultants (Gelcich et al. 2008b). TURFs are 88 interspaced with open access areas (OAAs) where seasonal closures and limits on catch size are used, but entry, within-season effort, and total catch are not restricted. The Chilean TURFs system 90 was initially (i.e., from the 1990s to the 2000s) successful and associated with positive ecological 
91 and economic benefits, such as the recovery of loco stocks, increased species richness inside

92 TURFs, and increased welfare and economic revenues (Castilla and Fernandez 1998, Defeo and

93 Castilla 2005, Gelcich et al. 2008a, 2012). OAAs produced the majority of catch and fishing

94 revenues however. While income from TURFs was largely supplemental, believed to represent

$957 \%$ to $41 \%$ of total incomes (Romero et al. 2016), it was thought to play an essential role in

96 securing fishers' livelihoods (Aburto et al. 2013, Van Holt 2012, Gelcich et al. 2017).

97

Though ecological conditions appear to have improved within TURFs (Castilla and

98 Fernández 1998, Gelcich et al. 2012), TURF profitability is thought to have declined over the last

99 decade (Gelcich et al. 2017). The development of abalone aquaculture in Asia has negatively

100 influenced international demand for loco, leading to a reduction in exports from Chile to Asia

101 (from 2,400 $\mathrm{mt}$ in 1993 to less than 1,000 mt in 2013), and a drop in the price of loco (Chávez et

102 al. 2010, Castilla et al. 2016). Furthermore, the cost of TURF maintenance, which includes

103 assessment, enforcement, and surveillance, is thought to have increased (based on perception

104 surveys; Gelcich et al. 2009, 2017). Assessments are typically conducted by private environmental

105 consultants, whose fees have increased in part because of the relatively small number of such

106 companies available in Chile (Gelcich et al. 2009, Davis et al. 2015). Additionally, extensive

107 illegal fishing (González et al. 2006, Andreu-Cazenave et al. 2017, Oyanedel et al. 2017) suggests

108 that local fishing organizations must dedicate significant time and resources to enforcement in

109 TURFs. Though the Chilean government recognizes that there is poaching activity and, in theory,

110 is responsible for apprehending and penalizing poachers, in practice the responsibility of detecting

111 poaching in TURFs often falls on fishing organizations. Many fishers now indicate they do not

112 have enough capacity (i.e. resources and time) for surveillance of their TURFs and consider

113 "government punishment of poachers to be ineffective" (Moreno and Revenga 2014, Davis et al. 
114 2015, Biggs et al. 2016). Thus, the combined influence of a lower price for loco and presumed 115 increased maintenance costs, with a reduced enforcement capacity, have likely increased 116 variability in financial returns and decreased the profitability of TURFs (Chávez et al. 2010, 117 Gelcich et al. 2010, 2017). In fact, in recent years (roughly 2010-2017), fishers appear to be relying 118 on TURFs less than initially (i.e., 1990s-2000s) and TURF exploitation now represents a smaller 119 fraction of fishers' overall incomes (Gelcich et al. 2017). This has coincided with an observed 120 increase in exploitation of OAAs (de Juan et al. 2017) and substantial illegal fishing of locos 121 (Andreu-Cazenave et al. 2017). Reduced incentives for the exploitation of a TURF could either 122 result in its abandonment (San Martín et al. 2010, Gelcich et al. 2017), its maintenance for purposes 123 other than fishing such as market access or social empowerment (Cancino et al. 2007, Zúñiga et 124 al. 2010, Aburto et al. 2013, Rosas et al. 2014, Gelcich et al. 2017), or its maintenance at a lower 125 but still positive level of profitability.

Potential positive or negative interactions between maintained TURFs and surrounding OAAs are unknown. The large TURF system of Chile offers opportunities to explore the consequences of spatial management on fisheries in surrounding areas. TURFs are expected to 129 secure fisheries harvests within their boundaries and provide incentives for sustainable use of 130 surrounding fishing grounds (Christy 1982). Recent studies in the Chilean system of TURFs have 131 shown higher potential egg production of two benthic species (the limpet Fissurella latimarginata 132 and the red sea urchin Loxechinus albus) within TURFs than under an open access scenario (67\% 133 and 52\% higher, respectively) (Blanco et al. 2017, Fernández et al. 2017), suggesting the potential 134 to enhance fishing opportunities both inside and outside TURFs. Negative impacts of TURFs and 135 other entry-restriction management and conservation tools beyond their limits are less well known. 136 Management spillover consisting of effort displacement from high-regulation TURFs to lower- 
137 regulation areas outside TURFs (analogous to the "fisheries squeeze effect" in the context of 138 marine protected areas; Attwood and Bennett 1995, Bohnsack 2000, Halpern et al. 2004) could be 139 expected to occur, potentially deteriorating opportunities in surrounding fishing grounds. Recent 140 reductions in TURF profitability may provide increased incentives for TURF users to increase 141 fishing effort in OAAs, possibly further eroding the sustainability and profitability of Chilean 142 coastal fisheries in these areas. The primary goals of this study were to analyze catch and catch rates within and outside of

144 TURFs to document any trends and interactions that might impact the ability of the TURF system 145 to meet the objectives of ensuring sustainability and increasing biological productivity of benthic 146 fishery resources. Specifically, we first examined and compared CPUE and CPUA indices (catch 147 rates) between TURFs and adjacent OAAs by fishing cove in 2015 for three important target 148 species (keyhole limpet (Fissurella spp.), kelp (Lessonia spp.) and red sea urchin (Loxechinus 149 albus)). Second, temporal dynamics in TURF and OAA catch rates were investigated by looking 150 at time series of CPUAs calculated for each management area by fishing cove and year. Finally, 151 to assess if catch rate differences between TURFs and adjacent OAAs observed in 2015 were 152 related to TURF implementation, a penalized regression model was developed to explain catch in 153 OAAs. The explanatory variables examined in the model were either related to proximal TURFs' 154 characteristics and activity (e.g., TURF age, TURF area fraction, TURF fishing effort), or 155 additional geospatial variables related to the spatial extent and context of OAAs (e.g., coastline 156 length, local productivity, proximity to urban areas).

\section{Methods}

\subsection{Data}


National data on catch and effort by fishing cove were obtained from the governmental agency SERNAPESCA (National Fisheries Service). Artisanal fishers are required to report 162 landings by species, weight and origin (i.e., TURF or OAA; Moreno and Revenga 2014). TURF 163 geographical layers were obtained from the governmental agency SUBPESCA (Undersecretary of 164 fisheries). Fishing coves considered for the study (Fig. 1) had at least one designated TURF 165 assigned to a fishers' organization (referred to here as a functioning TURF; i.e., an operative TURF 166 with a use agreement and quota in place or a stand-by TURF for which a quota has been assigned 167 in the last 4 years, but monitoring has not been conducted by the due date, Appendix 1).

The artisanal benthic fisheries of Chile target a variety of species, including crustaceans, mollusks, sea urchins, tunicates and several species of seaweed (Gelcich et al. 2010). Catch data 170 were obtained from landings reports, focusing on the most important benthic resources targeted in 171 TURFs. The primary target resource inside TURFs is the loco, which has the highest commercial 172 value (beach sale value: 11,647 US\$/mt; landings: 2,255 mt in 2011) (Moreno and Revenga 2014). 173 Loco extraction is banned in OAAs, and, therefore, only catches from inside TURFs were analyzed 174 for this species. Kelps (comprising the Lessonia nigrescens species complex, Lessonia 175 trabeculata, Macrocystis pyrifera and Macrocystis integrifolia) and the red sea urchin (Loxechinus 176 albus) are the largest landed benthic resources ranked by weight (landings: 300,000 mt and 177 31,901 mt for kelp and sea urchin, respectively, in 2011). We also considered catches of keyhole 178 limpets (comprising Fissurella spp., Fissurella costata, Fissurella cumingi, Fissurella 179 latimarginata, Fissurella picta, and Fissurella maxima), another economically important benthic 180 resource (beach sale value: 2,354 US\$/mt; landings: 1,785 mt in 2011). Individual catch reports 181 from 2000 through 2015 for these four main exploited benthic resources were aggregated by 182 fishing cove and month (an individual harvester could report catch several times in a month), and 
183 distinguished by their origin (i.e., inside or outside TURFs). Catches in OAAs (i.e., outside 184 TURFs) included catches gathered from artisanal boats or from the shore.

The number of active harvesters in 2016 per fishing cove was also obtained from 186 SERNAPESCA (most recent estimation, note that the number of fishers for 2015 was not 187 available). Individuals who have not operated for the last three successive years were removed 188 from the national registry. Chilean law distinguishes four categories of artisanal harvesters: 1) 189 Divers, who manually extract mollusks, crustaceans or echinoderms, or spearfish for reef fish, 190 usually operating from a boat; 2) Collectors, who harvest or collect seaweeds from the shore; 3) 191 Fishers, who are captains or crew members of an artisanal boat, from which they operate with nets, 192 including trammel nets, long lines, and hand lines; and 4) Ship owners, who are limited to one or 193 two artisanal boats, defined as 18 meters or less in length, and 50 tons or less. The different 194 categories are not mutually exclusive. Effort was estimated in terms of the number of divers (for 195 loco, limpet and sea urchin exploitation) or number of collectors (for kelp exploitation) registered 196 in a fishing cove and able to exploit the resource. Fishers' organizations that are granted a TURF 197 can only be comprised of licensed artisanal harvesters. However, not all licensed artisanal 198 harvesters are part of a fishers’ organization. Therefore, effort “inside” TURFs only considered 199 licensed harvesters who were also registered in the corresponding fishers' organization, while 200 effort "outside” TURFs considered all licensed harvesters registered in a particular fishing cove. 201 A small number of harvesters (about 10\%) were licensed in one fishing cove but associated with 202 fishing organizations in different fishing coves. To avoid overestimating effort per fishing cove, 203 the contribution of an individual harvester to effort in a cove was calculated by equally dividing 204 one unit of effort (i.e., one harvester) among the different fishing coves with which the harvester 205 was associated. 
Fishing area estimates, for both TURFs and OAAs in each cove, were calculated using

207

208

209

210

211

212

213

214

215

216

217

218

219

220

221

222 223 minus assigned TURFs areas.

224

225

226

227

228

different data and proxies. TURF areas were obtained through a Google Earth layer publicly available on the SUBPESCA website for 2016. Total fishing ground polygons (comprising TURFs and OAAs) were created per fishing cove based on sailing time and bathymetry (Appendix 2). Buffer zones of $17 \mathrm{~km}$ (alongshore cutoff) around fishing coves were produced in ArcGIS to represent total accessible fishing grounds for each cove. The 17-km cutoff was based on the average distance from the fishing cove center to fishing grounds potentially visited as determined by artisanal fisher survey results (Ruano-Chamorro et al. 2017). These 17-km buffers were then intersected with a bathymetric polygon consisting of the area between 0 and $20 \mathrm{~m}$ depth. The offshore width of these polygons was based on a typical maximum harvest depth of $20 \mathrm{~m}$ (González et al. 2006). These alongshore and offshore cutoffs are similar to those used by Castilla (1994) and Aburto et al. (2009) which applied an offshore limit of $30 \mathrm{~m}$ and an alongshore cutoff of $15 \mathrm{~km}$ based on travel distance with one full tank of gas. The 20-m isopleth was only available for central Chile (from $27^{\circ}$ to $36^{\circ}$, Fig. 1) whereas a 100 -m isopleth was available for the whole Chilean coast (source GEBCO). Estimates for the areas of the 0-20 m fishing ground depth range were derived from the areas of 0-100 m depth range using multiple linear regression (see Appendix 2 for details). Finally, estimates of OAA areas were calculated as total area of fishing grounds

\subsection{Catch rate comparisons between TURFs and OAAs in 2015}

Annual catches divided by the number of active months (several species are only landed during part of the year) of keyhole limpet, kelp, and red sea urchin were used to estimate CPUEs and CPUAs per fishing cove for 2015 (most recent complete year for catch data at the time of the 
study, SERNAPESCA). Loco's estimates were not compared since its extraction is banned in

230 OAAs, and, therefore, only catches from inside TURFs were available. CPUEs and CPUAs were

231 differentiated by their origin, i.e., catches inside TURFs or in OAAs, and then compared to one

232 another to determine differences in fisheries productivity. CPUEs for each fishing cove were

233 calculated as the catches inside or outside TURFs divided by the adjusted number of divers (or

234 collectors) (i.e., after having adjusted this number to account for harvesters associated with

235 multiple fishing coves) inside or outside TURFs, respectively. The number of licensed harvesters

236 in 2016 was the best available effort proxy for estimating CPUEs in 2015 even though this is a

237 crude estimate as it is unknown how many trips each individual took. CPUAs for each fishing cove

238 were calculated as the catches inside or outside TURFs divided by the total assigned TURF area

239 (inside) or the estimated OAA area (outside). For each group of species, differences between

240 CPUEs and CPUAs inside and outside TURFs were tested for statistical significance using a

241 nonparametric Wilcoxon signed-rank test. Reporting rates from TURFs and OAAs could differ

242 given higher enforcement capacity within TURFs (Ruano-Chamorro et al. 2017). We therefore

243 calculated what catch in OAAs would have to be for catch rates in OAAs to equal those in TURFs

244 (assuming full reporting in TURFs), and then deduced the misreporting rate in OAAs it would 245 imply for each species and catch rate metric.

246

247 2. 3 Temporal analyses of CPUAs inside and outside TURFs

248 CPUAs of loco, keyhole limpet, kelp, and red sea urchin were analyzed over time to 249 investigate temporal performance of TURFs and OAAs over the last two decades. Fisheries data 250 was only available at the scale of an entire fishing cove, prohibiting differentiation between 251 multiple TURFs associated with a single fishing cove. Estimated OAA areas from 2016 were 
252 adjusted over years according to implemented TURFs' area for that year and fishing cove

253 (implementation year of TURFs were available from the SUBPESCA data). Complementary

254 temporal analysis of CPUE trends was not feasible as the annual number of fishers was not

255 available at the fishing cove scale. Changes in CPUA over time may reflect changes in biomass,

256 changes in fishing effort, or changes in spatial management. If biomass were improving inside

257 TURFs, CPUAs in these areas might be expected to increase over time. Conversely, if TURFs

258 displaced fishing effort into OAAs, CPUAs in OAAs might be expected to decrease due to

259 overfishing (but may increase initially as increased effort fishes down stocks). Additionally, a

260 fishing cove can have several TURFs (up to 15 managed areas, but on average three). If the initial

261 TURF implemented in a given fishing cove was located in the best habitat (Wilen et al. 2012), then

262 fishing coves with multiple TURFs might experience sequential reductions in CPUAs. Finally, as

263 catch depends on effort, it is also possible that changes in CPUA reflect changes in fishing effort

264 over time (e.g., CPUA reductions arising due to reduced fishing effort independent of any changes

265 in fish stocks).

A linear mixed effects model (i.e., model 1) was used to estimate the temporal trend and

267 the effect of the number of TURFs per fishing cove on CPUAs inside and outside TURFs:

$$
\ln \left(C P U A_{s, i, t, a}\right)=\beta_{1} \text { year }_{t}+\beta_{2} N_{T U R F i, t}+\delta_{i}+\varepsilon_{s, i, t, a}
$$

268 In (1), the dependent variable is the log-transformed CPUA for species s, observed in the fishing

269 cove $i$, for year $t$, in area $a$ (inside or outside TURFs). $\beta_{1}, \beta_{2}$ are the unknown coefficients of the

270 fixed effects variables year (from 2000 to 2015) and $\mathrm{N}_{\mathrm{TURF}}$, the number of functioning (i.e.,

271 operative or stand by) TURFs per fishing cove for each year, respectively. $\delta_{i}$ is a random effect

272 for fishing cove $i$, to control for heterogeneity across fishing coves and $\varepsilon_{s, i, t, a}$ is the error term. 
To further disentangle the effects of time and number of TURFs per fishing cove on

274 CPUAs, an additional linear mixed effects model (i.e., model 2) was developed without the

275 variable $\mathrm{N}_{\text {TURF. }}$ Model 2 included a subsample of 57 fishing coves (29\% of the 196 coves

276 considered in this study) that have had a constant number of TURF(s) for at least 10 years.

277 Statistical estimation of coefficients was performed in R (R Core Team, 2018) with the

278 lme4 package (Bates et al. 2015). Marginal and conditional coefficients of determination, $\mathrm{r}^{2} \mathrm{~m}$ and

$279 \quad r^{2}$, respectively, were estimated with the MuMIn package (Nakagawa and Schielzeth 2013).

280

$281 \quad 2.4$ Elastic net regression model

The catches of keyhole limpet, kelp and red sea urchin from OAAs in 2015 were examined

283 to assess the impact of adjacent TURF characteristics and activity. Chile is divided into 15

284 administrative regions; fisheries for each of the species groups considered in this analysis generally

285 occur in only a subset of these regions (Appendix 3). As the great majority of limpet and kelp catch

286 occurred in the northern regions of Chile (specifically regions II, III, IV and V) and the great

287 majority of sea urchin catch occurred in the southern region (specifically, regions VIII, IX, XIV,

$288 \mathrm{X}$ and $\mathrm{XI}$ ), data for species-specific analyses were limited to these northern and southern zones

289 (see Section 3.1 for details regarding the basis for selecting these zones).

290 A regularized linear regression model, the elastic net regression (Zou and Hastie 2005, see

291 Appendix 4 for model development), was developed to explain catch per cove in OAAs, including

292 explanatory variables either related to proximal TURFs' characteristics and activity, or related to

293 geospatial context (e.g., area and coastline length) and number of fishers targeting a given species.

294 This model uses a penalized maximum likelihood method that allows a large number of variables

295 to be included with relatively few observations and prevents over-fitting issues prevalent in more 
common Ordinary Least Square (OLS) or stepwise regression methods (Friedman et al. 2010,

297 Morozova et al. 2015). The algorithm accomplishes variable selection by constraining the sum of

298 the magnitudes of normalized coefficients. A shrinkage penalty is included in the objective

299 function; it "shrinks" the effect of unimportant variables to select the simplest and most accurate

300

model. Two different values of the regularization parameter controlling the strength of the

301 shrinkage were considered; only results from the less restrictive regularization are shown here (see

302 Appendix 5 for results with the more restrictive regularization, i.e., a larger penalty that leads to

303 models with a smaller number of predictors with non-zero coefficients).

304

The response variables, i.e., catches in OAAs for limpet, kelp, and sea urchin, were log-

transformed before centering. We considered catch as the dependent variable instead of CPUEs

306 and CPUAs because we preferred a model including both effort and area as explanatory variables

307 simultaneously.

Given that effort displacement and any resulting ecological and social impacts are dynamic

processes, TURFs established for longer periods might be expected to have more significant effects on catches outside of TURFs. In order to assess these temporal effects, elastic net models included the variables number of years since the implementation of a TURF (Age_TURF) and

312 number of years since the establishment of the associated fishers' organization

313 (Age_Organization) (source SUBPESCA). In theory, a fisher's organization is established before

314 a TURF is implemented, but in some instances ( $30 \%$ of our fishing coves), the organization had

315 changed over time or several TURFs had merged or been split leading to the TURF being 316 implemented before the associated fishers’ organization. Since several fishers’ organizations can 317 operate in each cove and a fishing cove can have several TURFs, each associated with one fisher's 318 organization, the average and maximum values were calculated for both Age_TURF and 
Age_Organization. Spatial aspects of TURF use were captured by the variables $N_{-} T U R F$, Area_Fraction and Area_OA which measured the number of functioning TURFs per fishing cove,

321 the fraction of the total estimated fishing ground managed as TURFs and the total area of open 322 access grounds, respectively. The potential effects of fishing effort displacement should be greater 323 in fishing grounds with more TURFs and/or proportionately larger TURFs or smaller OAAs. 324 Fishing effort was included through the variables Harvesters_All, Harvesters_per_OAA and 325 Harvesters_per_TURFs, respectively, the total number of divers (or collectors) in OAAs, the 326 number of divers (or collectors) in OAAs divided by the OAAs area, and the number of divers (or 327 collectors) inside TURFs divided by the TURFs area. The predictions are that catch in OAAs 328 should increase with the total number of divers (or collectors) and decrease with the number of 329 divers (or collectors) per unit of area. Finally, the number of fisher's organizations per fishing 330 cove, $N \_O R G$, was used as another proxy for local effort levels and fisheries involvement.

Data on additional geospatial variables related to the spatial extent and context of OAAs 332 were also obtained to include in analyses of catch for each species. Coastline length was calculated 333 for fishing grounds adjacent to a fishing cove to capture differences in coastal habitats (e.g., 334 straight along beach and sinuous along cove leading to short and long coastline lengths, 335 respectively). Fractured coastlines with many small inlets are expected to be more favorable for 336 sea urchin productivity (Lawrence 2006) whereas linear beaches may represent regions of wide 337 continental shelf where unproductive sandy habitat is more common. As proximity to urban areas 338 might impact exploitation rates and other human pressures on benthic resources, a binary variable 339 was included to indicate if a fishing cove was within $50 \mathrm{~km}$ of one of the ten biggest cities of Chile 340 (source Instituto Nacional de Estadísticas). We also identified fishing coves close to fishing ports, 341 since increased market access could trigger higher effort and catches. Thus, if a fishing cove was 
342 within $50 \mathrm{~km}$ of one of the forty major fishing ports of Chile, total landings by weight (comprising

343 algae, fish, mollusk, crustacean, other) from these proximal fishing ports were summed together

344 and associated with this cove; if no fishing ports were within $50 \mathrm{~km}$, this variable was set to zero.

345 Finally, CPUEs for each species group (i.e., loco, keyhole limpet, kelp and sea urchin) within

346 TURFs were included as proxies for local abundance conditions. Abbreviations, definitions and

347 units for all variables included in the elastic net regression are given in Table 1.

348 Model parameters were estimated with the glmnet algorithm in R (Friedman et al. 2010, R

349 Development Core Team 2018). A bootstrapping process, randomly sampling the data with

350 replacement, was used to re-estimate the model 10,000 times. Coefficient means $(\bar{\beta})$, standard

351 errors $\left(\sigma_{\beta}\right)$ and probabilities of inclusion for each regression coefficient were calculated following

352 bootstrap iterations. We considered "highly important" predictors to be those with coefficients

353 retained in at least $80 \%$ of the bootstrap iterations; "important" predictors to be coefficients

354 retained in 60 to $80 \%$ of the iterations; and "moderately important" to be coefficients retained in

35540 to $60 \%$ of the iterations. Elastic net log-linear regression coefficients were transformed into

356 percent changes in catch for a given change in the predictor variable using the following formula:

$357 \% \Delta y=100 \cdot\left(e^{\beta . \Delta x}-1\right)$.

OLS models using either the full set of independent variables (OLS_all), using only TURF

359 related variables (OLS_TURF), using only geospatial context variables (OLS_Geo) or using only

360 variables selected by the elastic net model (OLS_elastic) were also run for comparison with the

361 elastic net outputs. P-values for the coefficients of each explanatory factor in the OLS models were

362 adjusted utilizing the Dunn-Šidák correction method for multiple statistical tests (Šidák 1967, Ury

363 1976). We considered the possibility of spatial heterogeneity in catch reporting by examining OLS

364 model residuals using Studentized Breusch-Pagan tests. 


\section{Results}

\subsection{Regional description of the system}

We analyzed 196 fishing coves with a total of 478 functioning TURFs in this study. Average TURF size was $1.5 \mathrm{~km}^{2}$ (ranging from $0.01 \mathrm{~km}^{2}$ to $39 \mathrm{~km}^{2}$ ). Average total TURF area per

370 fishing cove was $4( \pm 7.3) \mathrm{km}^{2}$ while average OAA area per fishing cove was $82( \pm 29) \mathrm{km}^{2}$. Limpet 371 and kelp catch in the northern regions (i.e., regions II, III, IV, V) accounted for 81.3\% and 84.8\% 372 of total national catch of each species group, respectively. Contrarily, $95.1 \%$ of sea urchin catch 373 and $77.6 \%$ of loco catch were landed in the southern regions (i.e., regions VIII, IX, XIV, X and 374 XI, Fig. 1, Appendix 3). The contrasting landing patterns were accompanied by differences in 375 TURFs' size. TURF average area per fishing cove was higher and more variable in southern 376 regions $\left(4.9 \pm 9.3 \mathrm{~km}^{2}\right)$ than in the northern region $\left(3.2 \pm 3.1 \mathrm{~km}^{2}\right)$, and OAA average sizes 377 associated with each fishing cove were larger in southern regions $\left(90.5 \pm 29.2 \mathrm{~km}^{2}\right)$ than in northern 378 regions $\left(58.0 \pm 103.0 \mathrm{~km}^{2}\right)$ (Table 2$)$. The sizes of OAAs were consistently larger than those of 379 TURFs, however the ratio between OAA and TURF size was similar between the north and the 380 south. In terms of effort, the number of divers (or collectors) that could fish in OAAs was higher 381 than the number that could fish in TURFs, with this difference being larger for fishing coves in the 382 south (Table 2).

3.2 Catch rate comparisons between TURFs and OAAs

CPUE and CPUA values for 2015 for each fishing cove were compared by their origin, i.e. 386 inside or outside TURFs (Fig. 2). CPUEs for limpet were observed to be higher inside TURFs 387 ( $\mathrm{p}=0.01)$. However, CPUEs were not significantly different between the two origins for kelp 
$388(\mathrm{p}=0.36)$ and sea urchin extraction $(\mathrm{p}=0.34)$, though their corresponding medians were higher

389 inside TURFs. For each of the three groups of species, CPUAs were significantly higher inside

390 TURFs ( $\mathrm{p}=2.1 \times 10^{-5}$ for limpet, $\mathrm{p}=5.4 \times 10^{-6}$ for kelp, and $\mathrm{p}=1 \times 10^{-3}$ for sea urchin). Overall, 391 median catch rates were at least 75\% higher inside TURFs (Table 3). With regard to catch rate

392 values across species, limpet and red sea urchin were caught at similar rates in terms of metric 393 tonnes per month per unit effort/area, whereas kelp was caught at a much higher rate, and loco was 394 caught at an intermediate rate. Assuming perfect reporting within TURFs, equal catch rates 395 between TURFs and OAAs imply 70\% to 99\% of catch from OAAs would be unreported. Higher 396 catch rates observed in TURFs therefore appear to be robust to catch misreporting

3.3 Temporal mixed effects analysis of area catch rates

Linear mixed effects models revealed that CPUAs had decreased significantly over time 400 inside TURFs, with rates of decrease of 7.8\%, 4\%, and 4.8\% per year for loco, limpet, and sea 401 urchin, respectively ( $<<0.05$, Table 4). For all species groups, CPUAs also significantly decreased 402 inside TURFs as the number of TURFs implemented in a fishing cove increased (between 10 and 403 29\% decrease in CPUA per additional TURF implemented, $\mathrm{p}<0.05$, Table 4). Effects of the 404 temporal driver Year were weaker in OAAs (Table 5). Only CPUAs for limpet significantly 405 decreased in OAAs over years (4.7\% decrease in CPUA/year, $\mathrm{p}<0.05$, Table 5). Interestingly, 406 CPUAs for kelp increased significantly outside of TURFs over time (3\% increase per year, $\mathrm{p}=0.02$, 407 Table 5) whereas there was no temporal trend inside TURFs. The number of TURFs did not have 408 any effect on CPUAs in OAAs for any of the species groups considered. Predicted values of 409 CPUAs inside TURFs from 2000 and 2015 were consistently higher than predicted values of 410 CPUAs within OAAs (Figure 3). When the models were restricted to just the subset of fishing 
411 coves having a constant number of TURFs (i.e., model 2), CPUAs were found to decrease 412 significantly over time inside TURFs for loco (8.5\% decrease per year), and outside TURFs for

413 limpet (2.5\% decrease per year, $\mathrm{p}<0.05$, Tables 4 and 5). Differences between conditional $\mathrm{r}^{2}{ }_{\mathrm{c}}$ and 414 marginal $r^{2}$ show that $40 \%$ to $80 \%$ of variability is due to spatial heterogeneity across fishing 415 coves (Tables 4 and 5).

$417 \quad 3.4$ Elastic net regression of OAA catch

\subsubsection{OLS and elastic net regressions comparison}

Catch of limpet, kelp, and sea urchin in OAAs were examined to resolve the effect of TURFs on adjacent areas in 2015 (loco is not included in OLS and elastic net regressions since its

421 extraction is banned in OAAs). OLS models were inconclusive, yielding no significant predictors

422 of catches outside TURFs though a considerable proportion of the variances were explained 423 (adjusted $\mathrm{r}^{2}=0.31$ for limpet, 0.55 for kelp, and 0.34 for sea urchin, Table 6). Geospatial variables 424 were found to explain a greater amount of variance than TURF variables in OLS models for all 425 species. Elastic net regression models explained similar proportions of variance as the OLS 426 models, but with fewer variables (adjusted $r^{2}=0.31$ for limpet, 0.55 for kelp, and 0.51 for sea 427 urchin, Table 6).

428

429 3.4.2 Predictors selected by the elastic net regression of OAA catch

430 Contrasting results from the elastic net regression model were found for the three groups 431 of species, with different predictors selected by the penalized model in explaining OAA catches 432 (Table 7). All "highly important predictors" retained to explain catch in OAAs for the three species 433 groups were related to the geospatial context. The predictor Urban_Area was selected in 83.69\% 
434 of the 10,000 bootstraps when modeling limpet catches and $99.73 \%$ of the bootstraps when 435 modeling kelp extraction, being the strongest identified driver of catch outside of TURFs in both 436 cases. This predictor exhibited a negative relationship with catches outside TURFs for both species 437 groups, with lower catches in the OAAs for limpet (33\% decrease for coves within $50 \mathrm{~km}$ to urban 438 areas compared to those far from urban areas) and kelp (72\% decrease) in fishing coves close to 439 urban areas. Additional predictors for catch of limpet outside TURFs included Area_OAA ${ }^{2}$ 440 (selected in 60.35\% of cases) and Area_fraction (selected in $41.86 \%$ of the bootstraps; definitions 441 of predictors in Table 1 ). There was a $0.08 \%$ reduction in limpet catch per $10 \mathrm{~km}^{2}$ of additional 442 OAA area and a $1.5 \%$ reduction per $1 \%$ increase in the fraction of the total area that is TURF. Several variables were found to be important predictors of kelp catches in OAAs. Loco 444 CPUEs inside TURF (Loco_per_diver) was a highly important, positive predictor of outside 445 catches of kelp and was included in $91.11 \%$ of the bootstraps (42\% increase of kelp catch in OAAs 446 for every additional $1 \mathrm{mt}$ catch of loco per diver within the TURF, with the average loco catch 447 being $0.46 \mathrm{mt}$ loco/diver). Similarly, higher catch rates of kelp inside TURFs were associated with 448 higher catches of kelp outside (1.4\% increase of kelp catch outside a TURF for every additional 1 449 mt catch of kelp per collector within the TURF, with the average kelp catch being $8.6 \mathrm{mt}$ 450 kelp/collector). Counterintuitively, lower catches of kelp outside of TURFs were associated with 451 fishing coves that had larger OAAs (11\% decrease in catch for every additional $10 \mathrm{~km}^{2}$ of OAA 452 area; Area_OAA and Area_OA $A^{2}$ were selected in at least $80 \%$ of bootstraps). Lower catches of 453 kelp outside of TURFs were associated with fishing coves that had older TURFs (e.g., for every 454 year increase in Age_TURF_max, there is a $~ 8 \%$ decrease in catch; Age_TURF_mean and 455 Age_TURF_max were included in $73.03 \%$ and $84.40 \%$ of the bootstraps) and fishing coves with a 456 higher fraction of fishing grounds managed as TURFs ( $0.8 \%$ decrease for every $1 \%$ increase in the 
457 fraction of area designated as TURFs; Area_fraction was selected in $47.36 \%$ of models). Finally,

458 lower catches of kelp in OAAs were observed in fishing coves with several fishers' organizations

459 (4.4\% decrease for every additional organization). The model indicates that OAAs with higher

460 catches of kelp tended to be smaller, outside of urban centers, in areas with productive loco

461 fisheries, and have fewer, younger, and proportionately smaller proximate TURFs.

462 Higher catches of sea urchin in OAAs were associated with fishing coves that have longer

463 coastline lengths (13\% increase in catch for every additional $10 \mathrm{~km}$ of coastline). This predictor

464 was highly important in explaining catch of sea urchin (selected in $98.98 \%$ of cases). A decrease

465 of sea urchin catch in OAAs was observed in fishing coves that had older TURFs (3\% decrease in

466 catch for every additional year since TURF implementation). The related variables

467 Age_TURF_max and Age_TURF_mean were included in $47.3 \%$ and $47.0 \%$ of the bootstraps, 468 respectively.

\section{Discussion}

We evaluated temporal and spatial trends in catch and catch rates for TURFs and OAAs in

472 Chile. This study is the first to consider fishing coves all along the Chilean coast to understand the

473 TURF system in its entirety (TURFs and their surrounding areas) over two decades. Though

474 increased CPUEs inside of TURFs compared to OAAs has been demonstrated in previous

475 literature (Castilla and Fernández 1998, Gelcich et al. 2012, Defeo et al. 2016), most studies have

476 focused on small-scale projects in specific regions of the country. The most spatially extensive

477 study was based on a systematic literature review of the effects of TURFs on ecosystem services

478 in Chile considering 268 study sites all along the Chilean coast (Gelcich et al. 2019). It showed

479 that TURFs sustain biodiversity and all typologies of ecosystem services (i.e., supporting, 
480 provisioning, regulating and cultural services), but stressed a lack of studies addressing potential 481 negative or unpredicted consequences of TURFs and a need to better understand changes over time 482 (Gelcich et al. 2019). Our study expands the scale of previous analyses, focusing on the comparison 483 between TURFs and OAAs, and shows that median catch rates (CPUAs and CPUEs) of benthic 484 resources were at least 75\% higher inside TURFs than in surrounding areas. To the extent that 485 these catch rates are indicators of biomass, this result points out that Chilean TURFs appear to 486 align with their main objectives in 2015, i.e. "ensure the sustainability of artisanal fishing through 487 the assignment of natural banks" and "maintain and increase the biological productivity of benthic 488 resources”. However, our study also indicates that catch rates have been steadily declining within 489 TURFs and that TURFs may impact catch levels in surrounding OAAs, both of which are potential 490 risks to system sustainability. Three possible mechanisms could produce higher CPUASs and CPUEs in TURFs: 1) 492 recovered biomass could have built up and improved catch rates within TURFs over time, 2) 493 TURFs could have been implemented in areas of better habitat and higher quality grounds, and/or 494 3) effort displacement following the implementation of TURFs could have degraded OAAs over 495 time. CPUAs and CPUEs of loco, keyhole limpet, kelp, and red sea urchin in TURFs and OAAs 496 were analyzed to investigate differences between areas and over time. Additionally, catch of 497 keyhole limpet, kelp, and red sea urchin in OAAs was investigated to resolve any impacts of 498 proximal TURFs. Our findings indicate that CPUAs and CPUEs are consistently larger inside 499 TURFs but that CPUAs have been decreasing in TURFs over time and also with the number of 500 TURFs implemented by fishing cove. Further, a weak negative impact of proximal TURFs on 501 catches in OAAs was also found. This evidence appears to provide the strongest support for the 502 hypothesis that TURFs were selectively implemented in the best fishing grounds since catch rates 
503 are higher inside TURFs throughout our data, yet declining over time and with the addition of new

504 TURFs. Additionally, the small negative effect of proximal TURFs of OAA catches could result

505 from effort displacement and suggests management spillover. Declining catch rates over time

506 within TURFs does not appear to support the hypothesis that catch rates are improved in TURFs

507 due to a recovery of biomass. As we were only able to calculate CPUAs over time, this finding

508 could result from consistent reductions in effort. Nationally, however, the number of registered

509 divers has been constant while the number of collectors has increased over the last decade

510 (Appendix 6, Sernapesca 2015). It is not clear how average fishing effort by registered harvesters

511 (e.g., number of trips/harvester) may have changed over this period, and TURFs may now be used

512 less intensively. Interestingly, for some species, CPUAs were found to have been decreasing in

513 fishing coves that have had a constant number of TURF(s) for at least 10 years, indicating that the

514 observed temporal change in CPUA is not only due to selective implementation of TURFs, but

515 possibly due to changes in the local environment or the intensity of fishing effort.

516 Exogenous geospatial factors (e.g., coastline, OAA areas, urban areas) were the main

517 drivers explaining variability of catches in OAAs across fishing coves for 2015 (based on selection

518 in elastic net regressions and the greater amount of variance explained in the OLS analyses

519 including just these variables, Table 5). Geospatial predictors always had a higher percentage of

520 inclusion when compared to TURF management-related predictors (Table 6). The negative

521 relationship between catches of limpet and kelp in OAAs and proximity to urban centers could be

522 due to higher historical fishing pressure and deteriorated environments in more populated urban

523 areas. Additionally, catch of kelp, a lower value product, in OAAs could also be higher in rural

524 areas where there are fewer economic opportunities and thus lower opportunity costs for fishers.

525 Fishing coves with longer coastline lengths seem to support higher catches of sea urchin, 
526 suggesting environmental factors related to coastline complexity may be the principal drivers for

527 sea urchin abundance and availability. The effect of TURFs on catches in OAAs was especially

528 weak for limpet and sea urchin (TURF-related predictors selected for 40 to 50\% of bootstraps).

529 However, when predictors related to TURFs' characteristics and activity (i.e., time since TURF

530 registration or fisher organization implementation, and fraction of TURF area) were retained in

531 the models, they consistently displayed a negative relationship with OAA catches.

532

Several aspects of the Chilean TURF system and available data are worth mentioning to

533 provide additional context and inform interpretation of results. First, this study only considered

534 fishing coves with at least one functioning TURF (operative or stand by) in 2016. Gelcich et al.

535 (2017) revealed that about 40\% of TURFs are inactive or currently abandoned in Chile. TURFs

536 that have been abandoned would have increased OAAs, inferring that CPUA values could be lower

537 in OAAs than actually observed (but possibly higher within TURFs). Second, it is possible that

538 temporal dynamics and interactions between TURFs and OAAs may have changed over time. Our

539 analysis began in 2000, however TURF management commenced in the early 1990s and

540 approximately $18 \%$ of the TURFs considered here were initiated prior to 2000 . Further analysis

541 and investigation are needed to determine temporal changes and management interactions during

542 the first decade of TURF management. Finally, TURFs are a management tool typically used to

543 achieve sustainable fisheries and resource extraction within their boundaries (Christy 1982,

544 Aceves-Bueno and Halpern 2018), though it is possible that some TURFs in Chile are maintained

545 today for non-extractive purposes. For example, Chilean TURFs have been argued to build 546 leadership and social cohesion among fishers (Rosas et al. 2014, Gelcich et al. 2019) and may offer

547 benefits for conservation or restoration of benthic habitats (Gelcich et al. 2008a, Blanco et al. 2017, 
548 Fernández et al. 2017). Non-extractive social or ecological benefits arising from maintained

549 TURFs in Chile are not considered here but are important areas for future research.

While this analysis was able to discern broad temporal and spatial trends by evaluating

551 catch and catch rates across 196 fishing coves over two decades, the available data was generally

552 coarse and requires consideration for potential biases. Recent studies have shown that misreporting

553 can be a problem in officially reported catches (Oyanedel et al. 2017, Ruano-Chamorro et al.

554 2017), particularly with respect to locos (official catch is thought to only account for 14-30\% of

555 total loco extraction in Chile). As this research was primarily focused on relative trends and

556 comparisons among catch and catch rates in OAAs and TURFs, misreporting was considered to

557 only be problematic if it were non-uniform over space or time or differing between TURFs and

558 OAAs. We examined the possibility of spatial heterogeneity in catch reporting by examining OLS

559 model residuals using Studentized Breusch-Pagan tests and found no evidence of heterogeneous

560 error variances across observations ( $>>0.05$, Appendix 7). Additionally, higher catch rates

561 observed in TURFs appeared to be robust to catch misreporting. Estimation of OAAs and fishing

562 effort were based on a number of assumptions regarding fishing behavior. The negative

563 relationship found between catches of kelp and limpet and OAA size appears counterintuitive:

564 higher catches outside of TURFs were observed in fishing coves with smaller OAAs. It is possible

565 that total fishing ground boundaries based on average travel distance (Ruano-Chamorro et al.

566 2017) and bathymetry were too liberal and thus OAA areas were over-estimated in some instances

567 (e.g., coastline complexity and wave exposure might limit sailing of small boats and the effective

568 fishing area). Future research could incorporate fishers' mobility among proximal fishing coves in

569 fishing effort estimates, though it would require extensive field studies to determine the

570 appropriate spatial range of effort. Finally, though CPUE values were found to be lower in OAAs, 
571 this metric relies on a crude estimate of effort as information on the number of trips or dive

572 durations was not available. Nevertheless, consistency between CPUE and CPUA measures

573 (metrics were found to be positively correlated in all areas) suggests that our CPUE values were a

574 reasonable reflection of catch rates around fishing coves.

575 Various factors related to local governance could further explain low CPUAs and CPUEs

576 observed in OAAs as well as the decrease of CPUAs observed over time. Such variables could

577 include leadership, organizations' degree of cooperation, government support and governance

578 network structure. A social-ecological-system framework (Ostrom 2007) was found to be useful

579 for examining these variables and associated institutional regimes in Mexico and Costa Rica

580 (Basurto et al. 2013, García Lozano and Heinen 2016). This type of analysis would require

581 extensive fieldwork, and, therefore, the spatial scale of such analysis would likely be considerably

582 smaller than that used in this study. Nevertheless, application of such an approach to the Chilean

583 context represents an important avenue for future work that could enhance our understanding of

584 the interaction between institutional factors and successful TURFs-based fisheries management.

585 Many countries are transitioning marine resource management from common property

586 systems towards rights-based approaches (e.g., individual transferable quotas, catch shares, or

587 TURFs), driven by concerns related to sustainability and resource stewardship (Orensanz et al.

588 2005, Nguyen Thi Quinh et al. 2017). Although the influence of MPAs on surrounding areas and

589 fisheries sustainability are now well known, enhancing biomass through larval export and adult

590 spillover (Gell and Roberts 2003, Harrison et al. 2012) or negatively impacting surrounding

591 unprotected waters through "fishery squeeze" and/or "fishing the line” behavior (Kellner et al.

592 2007, Caveen et al. 2014, Abbott and Haynie 2012), the impacts of TURFs on surrounding areas

593 have been poorly documented. This study contributes to a better understanding of management 
594 spillover between TURFs and OAAs. Whereas the impacts of TURFs appeared weak in this study, 595 possibly growing over time given the negative relationship with TURF age variables, CPUEs and 596 CPUAs were significantly lower in OAAs. This finding suggests that OAAs, whose total area is 597 more than 50 times larger than grounds currently managed as TURFs, may be substantially 598 degraded and overfished. Several authors have suggested that resources in OAAs might be heavily 599 exploited and even depleted (González et al. 2006, Orensanz and Parma 2010, Andreu-Cazenave 600 et al. 2017, de Juan et al. 2017, Oyanedel et al. 2017, Ruano-Chamorro et al. 2017). Interestingly, 601 our results do not show significant temporal declines in OAA CPUAs, suggesting either shifts in 602 effort over time or that OAAs were depleted prior to 2000. The research presented here suggests 603 that TURFs could place additional burden on already heavily fished OAAs. The current fisheries 604 management regime in Chile includes limited assessment or monitoring of OAAs. It appears 605 important that more attention be focused on OAAs, and on the system as a whole. By knowing 606 that TURFs affect fisheries in OAAs, stocks outside managed areas may be more effectively 607 controlled, provided that existing harvest controls outside of TURFs (i.e., bans, minimum legal 608 size) are better enforced.

609 The Chilean TURF network is the largest worldwide, has been extensively studied and 610 may, therefore, provide useful guidance for countries or regions transitioning toward rights-based 611 approaches. For example, many Latin America countries have similar spatial management policies 612 for small-scale fisheries (Mexico, Brazil, Costa Rica, Ecuador, Galapagos) and also share similar 613 capacities for enforcement, dependence on a few high-value benthic species, extended OAAs, and 614 co-management regimes (da Silva 2004, Beitl 2011, Defeo et al. 2016, Garcia Lozano and Heinen 615 2016). Determining whether or not unintended impacts of TURFs on OAAs, similar to those found 616 here, exist in these regions is an important area for future research. 
Acknowledgments

The authors thank S. de Juan, B. Bularz, S. López and M. Andreu-Cazenave for their help with the data collection. We thank the presidents and secretaries of the disparate fishing organizations who met with us in the fishing coves of Algarrobo, Cascabelles, Chigualoco, El

622 Quisco, Horcon, Pichicuy and Quintay for their trust and commitment in sharing their knowledge 623 about the TURFs system in Chile. We also thank two anonymous reviewers for constructive 624 criticisms on preliminary versions of the paper. This work was supported by the Iniciativa 625 Científica Milenio from Ministerio de Economía, Fomento y Turismo de Chile (Project Fondecyt: 6261130976 to MFB), the Virginia Sea Grant Graduate Research Fellowship (NA14OAR4170093 to

627 JB), the Virginia Institute of Marine Science Foundation, and the W\&M Reves Center for 628 international studies. This is contribution No. 3843 of the Virginia Institute of Marine Science, 629 William \& Mary.

630

$631 \quad$ Literature Cited

632 Abbott, J.K., Haynie, A.C., 2012. What are we protecting? Fisher behavior and the unintended 633 consequences of spatial closures as a fishery management tool. Ecol Appl 22, 762-777. 634 https://doi.org/10.1890/11-1319.1

635 Aburto, J., Thiel, M., Stotz, W., 2009. Allocation of effort in artisanal fisheries: The importance 636 of migration and temporary fishing camps. Ocean Coast Manage 52, 646-654. https://doi.org/10.1016/j.ocecoaman.2009.10.004

638 Aburto, J., Gallardo, G., Stotz, W., Cerda, C., Mondaca-Schachermayer, C., Vera, K., 2013. 639 Territorial user rights for artisanal fisheries in Chile - intended and unintended outcomes. 640 Ocean Coast Manage 71, 284-295. https://doi.org/10.1016/j.ocecoaman.2012.09.015 
641

642

643

644

645

646

647

648

649

650

651

652

653

654

655

656

657

658

659

660

661

662

663

664

665

666

667

668

Aburto, J., Stotz, W., 2013. Learning about TURFs and natural variability: Failure of surf clam management in Chile. Ocean Coast Manage 71, 88-98. https://doi.org/10.1016/j.ocecoaman.2012.10.013

Aburto, J.A., Stotz, W.B., Cundill, G., 2014. Social-Ecological Collapse: TURF Governance in the Context of Highly Variable Resources in Chile. Ecol Soc 19, 2. http://dx.doi.org/10.5751/ES-06145-190102

Aceves-Bueno, E., Halpern, B.S., 2018. Informing the design of territorial use rights in fisheries from marine protected area theory. Mar Ecol Prog Ser 596, 247-262. https://doi.org/10.3354/meps12571

Andreu-Cazenave, M., Subida, M.D., Fernandez, M., 2017. Exploitation rates of two benthic resources across management regimes in central Chile: Evidence of illegal fishing in artisanal fisheries operating in open access areas. PLOS ONE 12, e0180012. https://doi.org/10.1371/journal.pone.0180012

Asche, F., Gordon, D.V., Jensen, C.L., 2007. Individual Vessel Quotas and Increased Fishing Pressure on Unregulated Species. Land Econ 83, 41-49. https://doi.org/10.3368/le.83.1.41

Attwood, C.G., Bennett, B.A., 1995. Modelling the effect of marine reserves on the recreational shore-fishery of the South-Western Cape, South Africa. Afr J Mar Sci 16, 227-240. https://doi.org/10.2989/025776195784156458

Basurto, X., Gelcich, S., Ostrom, E., 2013. The social-ecological system framework as a knowledge classificatory system for benthic small-scale fisheries. Global Environmental Change 23, 1366-1380. https://doi.org/10.1016/j.gloenvcha.2013.08.001

Bates, D., Mächler, M., Bolker, B., Walker, S., 2015. Fitting Linear Mixed-Effects Models Using lme4. J Stat Softw 67, 1-48. https://doi.org/10.18637/jss.v067.i01

Beddington, J.R., Agnew, D.J., Clark, C.W., 2007. Current Problems in the Management of Marine Fisheries. Science 316, 1713-1716. https://doi.org/10.1126/science.1137362

Beitl, C. M., 2011. Cockles in custody: the role of common property arrangements in the ecological sustainability of mangrove fisheries on the Ecuadorian coast. International Journal of the Commons 5(2), 485-512. http://doi.org/10.18352/ijc.285 
Bernal, P.A., Oliva, D., Aliaga, B., Morales, C., 1999. New regulations in Chilean Fisheries and Aquaculture: ITQ’s and Territorial Users Rights. Ocean Coast Manage 42, 119-142. https://doi.org/10.1016/S0964-5691(98)00049-0

Biggs, D., Amar, F., Valdebenito, A., Gelcich, S., 2016. Potential Synergies between NatureBased Tourism and Sustainable Use of Marine Resources: Insights from Dive Tourism in Territorial User Rights for Fisheries in Chile. PLOS ONE 11. http://dx.doi.org/10.1371/journal.pone.0148862

Blanco, M., Ospina-Álvarez, A., González, C., Fernández, M., 2017. Egg production patterns of two invertebrate species in rocky subtidal areas under different fishing regimes along the coast of central Chile. PLOS ONE 12, e0176758. https://doi.org/10.1371/journal.pone.0176758

Bohnsack, J.A., 2000. A comparison of the short-term impact of no-take marine reserves and minimum size limits. B Mar Sci 66, 635-650.

Branch, T.A., 2009. How do individual transferable quotas affect marine ecosystems? Fish Fish10, 39-57. https://doi.org/10.1111/j.1467-2979.2008.00294.x

Cancino, J.P., 2007. Collective Management and Territorial Use Rights: The Chilean Small-scale Loco Fishery Case. ProQuest.

Castilla, J., 1994. The Chilean Small-Scale Benthic Shellfisheries and the Institutionalization of New Management Practices. Ecology International Bulletin 47-63.

Castilla, J.C., Fernández, M., 1998. Small-scale benthic fisheries in chile: on co-management and sustainable use of benthic invertebrates. Ecol Appl 8, S124-S132.

Castilla, J.C., Espinosa, J., Yamashiro, C., Melo, O., Gelcich, S., 2016. Telecoupling Between Catch, Farming, and International Trade for the Gastropods Concholepas concholepas (Loco) and Haliotis spp. (Abalone). J Shellfish Res 35, 499-506. https://doi.org/10.2983/035.035.0223

Caveen, A., Polunin, N., Gray, T., Stead, S.M., 2014. The Controversy over Marine Protected Areas: Science meets Policy. Springer. 
Chávez, C., Dresdner, J., Quiroga, M., Baquedano, M., Gonzalez, N., Castro, R., 2010. Evaluación socio-económica de la pesquería del recurso loco asociada al régimen de áreas de manejo, como elemento de decisión para la administración pesquera. (No. Informe Final. Proyecto FIP 2008-31).

Christy, F.T., 1982. Territorial Use Rights in Marine Fisheries: Definitions and Conditions. UN Food \& Agriculture Organisation.

Costello, C., Gaines, S., Lynham, J., 2008. Can catch shares prevent fisheries collapse? Science 321, 1678-1681. https://doi.org/10.1126/science.1159478

Costello, C., Ovando, D., Hilborn, R., Gaines, S.D., Deschenes, O., Lester, S.E., 2012. Status and Solutions for the World's Unassessed Fisheries. Science 338, 517-520. https://doi.org/10.1126/science.1223389

Davis, K.J., Kragt, M.E., Gelcich, S., Burton, M., Schilizzi, S., Pannell, D.J., 2015. Why are Fishers not Enforcing Their Marine User Rights? Environ Resour Econ 1-21. doi:10.1007/s10640-015-9992-z

da Silva, P.P., 2004. From common property to co-management: lessons from Brazil’s first maritime extractive reserve. Mar Policy 28, 419-428. https://doi.org/10.1016/j.marpol.2003.10.017

de Juan, S., Gelcich, S., Fernández, M., 2017. Integrating stakeholder perceptions and preferences on ecosystem services in the management of coastal areas. Ocean Coast Manage 136, 38-48. https://doi.org/10.1016/j.ocecoaman.2016.11.019

Defeo, O., Castilla, J.C., 2005. More than One Bag for the World Fishery Crisis and Keys for Co-management Successes in Selected Artisanal Latin American Shellfisheries. Rev Fish Biol Fisher 15, 265-283. https://doi.org/10.1007/s11160-005-4865-0

Defeo, O., Castrejón, M., Pérez-Castañeda, R., Castilla, J.C., Gutiérrez, N.L., Essington, T.E., Folke, C., 2016. Co-management in Latin American small-scale shellfisheries: assessment from long-term case studies. Fish Fish 17, 176-192. https://doi.org/10.1111/faf.12101

FAO, 2014. The State of World Fisheries and Aquaculture 2014. Food and Agriculture Organization of the United Nations, Rome. 
724 Fernández, M., Blanco, M., Ruano-Chamorro, C., Subida, M.D., 2017. Reproductive output of

725

726

727

728

729

730

731

732

733

734

735

736

737

738

739

740

741

742

743

744

745

746

747

748

749

two benthic resources (Fissurella latimarginata and Loxechinus albus) under different management regimes along the coast of central Chile. Lat am jaquat res 45, 391-402. https://doi.org/10.3856/vol45-issue2-fulltext-14

Friedman, J., Hastie, T., Tibshirani, R., 2010. Regularization Paths for Generalized Linear Models via Coordinate Descent. J Stat Softw 33. https://doi.org/10.18637/jss.v033.i01

García Lozano, A.J., Heinen, J.T., 2016. Identifying Drivers of Collective Action for the Comanagement of Coastal Marine Fisheries in the Gulf of Nicoya, Costa Rica. Environmental Management 57, 759-769. https://doi.org/10.1007/s00267-015-0646-2

Gelcich, S., Godoy, N., Prado, L., Castilla, J.C., 2008a. Add-on conservation benefits of marine territorial user rights fishery policies in central Chile. Ecol Appl 18, 273-281. https://doi.org/10.1890/06-1896.1

Gelcich, S., Kaiser, M.J., Castilla, J.C., Edwards-Jones, G., 2008b. Engagement in comanagement of marine benthic resources influences environmental perceptions of artisanal fishers. Environ Conserv 35, 36-45. https://doi.org/10.1017/S0376892908004475

Gelcich, S., Godoy, N., Castilla, J.C., 2009. Artisanal fishers’ perceptions regarding coastal comanagement policies in Chile and their potentials to scale-up marine biodiversity conservation. Ocean Coast Manage 52, 424-432. https://doi.org/10.1016/j.ocecoaman.2009.07.005

Gelcich, S., Hughes, T.P., Olsson, P., Folke, C., Defeo, O., Fernández, M., Foale, S., Gunderson, L.H., Rodríguez-Sickert, C., Scheffer, M., others, 2010. Navigating transformations in governance of Chilean marine coastal resources. PNAS 107, 16794-16799. https://doi.org/10.1073/pnas.1012021107

Gelcich, S., Fernández, M., Godoy, N., Canepa, A., Prado, L., Castilla, J.C., 2012. Territorial User Rights for Fisheries as Ancillary Instruments for Marine Coastal Conservation in Chile. Conserv Biol 26, 1005-1015. https://doi.org/10.1111/j.1523-1739.2012.01928.x 
Gelcich, S., Cinner, J., Donlan, C.J., Tapia-Lewin, S., Godoy, N., Castilla, J.C., 2017. Fishers’ perceptions on the Chilean coastal TURF system after two decades: problems, benefits, and emerging needs. B Mar Sci 93. http://dx.doi.org/10.5343/bms.2015.1082

Gelcich, S., Martínez-Harms, M.J., Tapia-Lewin, S., Vasquez-Lavin, F., Ruano-Chamorro, C., 2019. Comanagement of small-scale fisheries and ecosystem services. Conserv Lett 12:e12637. https://doi.org/10.1111/conl.12637

Gell, F.R., Roberts, C.M., 2003. Benefits beyond boundaries: the fishery effects of marine reserves. Trends Ecol Evol 18, 448-455. https://doi.org/10.1016/S0169-5347(03)00189-7

González, J., Stotz, W., Garrido, J., Orensanz, J.M., Parma, A.M., Tapia, C., Zuleta, A., 2006. The Chilean TURF system: how is it performing in the case of the loco fishery? B Mar Sci 78, 499-527.

Halpern, B.S., Gaines, S.D., Warner, R.R., 2004. Confounding effects of the export of production and the displacement of fishing effort from marine reserves. Ecol Appl 14, 1248-1256. https://doi.org/10.1890/03-5136

Harrison, H.B., Williamson, D.H., Evans, R.D., Almany, G.R., Thorrold, S.R., Russ, G.R., Feldheim, K.A., van Herwerden, L., Planes, S., Srinivasan, M., Berumen, M.L., Jones, G.P., 2012. Larval Export from Marine Reserves and the Recruitment Benefit for Fish and Fisheries. Curr Biol 22, 1023-1028. https://doi.org/10.1016/j.cub.2012.04.008

Kellner, J.B., Tetreault, I., Gaines, S.D., Nisbet, R.M., 2007. Fishing the line near marine reserves in single and multispecies fisheries. Ecol Appl 17, 1039-1054. https://doi.org/10.1890/05-1845

Hilborn, R., Stokes, K., Maguire, J.-J., Smith, T., Botsford, L.W., Mangel, M., Orensanz, J., Parma, A., Rice, J., Bell, J., Cochrane, K.L., Garcia, S., Hall, S.J., Kirkwood, G.P., Sainsbury, K., Stefansson, G., Walters, C., 2004. When can marine reserves improve fisheries management? Ocean Coast Manage 47, 197-205. https://doi.org/10.1016/j.ocecoaman.2004.04.001

Kratz, B., Block, W.E., 2013. Privatize to Save the Fish. World Futures Review 5, 256-265. https://doi.org/10.1177/1946756713500025 
Lawrence, J.M., 2006. Edible Sea Urchins: Biology and Ecology. Elsevier.

Moreno, A., Revenga, C., 2014. The System of Territorial Use Rights in Fisheries in Chile. The Nature Conservancy, Arlington, Virginia, USA.

Morozova, O., Levina, O., Uusküla, A., Heimer, R., 2015. Comparison of subset selection methods in linear regression in the context of health-related quality of life and substance abuse in Russia. BMC Med Res Methodol 15. https://doi.org/10.1186/s12874-015-0066-2

Murawski, S.A., Wigley, S.E., Fogarty, M.J., Rago, P.J., Mountain, D.G., 2005. Effort distribution and catch patterns adjacent to temperate MPAs. ICES J. Mar. Sci. 62, 11501167. https://doi.org/10.1016/j.icesjms.2005.04.005

Nakagawa, S., Schielzeth, H., 2013. A general and simple method for obtaining $\mathrm{R}^{2}$ from generalized linear mixed-effects models. Methods Ecol Evol 4, 133-142. https://doi.org/10.1111/j.2041-210x.2012.00261.x

Nguyen Thi Quynh, C., Schilizzi, S., Hailu, A., Iftekhar, S., 2017. Territorial Use Rights for Fisheries (TURFs): State of the art and the road ahead. Mar Policy 75, 41-52. https://doi.org/10.1016/j.marpol.2016.10.004

Orensanz, J.M., Parma, A.M., Jerez, G., Barahona, N., Montecinos, M., Elias, I., 2005. What are the Key Elements for the Sustainability of "S-Fisheries”? Insights from South America. B Mar Sci 76, 527-556.

Orensanz, J.M., Parma, A.M., 2010. Chile: territorial use rights successful experiment? Samudra report 55.

Ostrom, E., 2007. A diagnostic approach for going beyond panaceas. PNAS 104, 15181-15187. https://doi.org/10.1073/pnas.0702288104

Oyanedel, R., Keim, A., Castilla, J.C., Gelcich, S., 2017. Illegal fishing and territorial user rights in Chile. Conserv Biol. 32 https://doi.org/10.1111/cobi.13048

R Core Team, 2018. R: A language and environment for statistical computing. R Foundation for Statistical Computing, Vienna, Austria. Available online at https://www.R-project.org/. 
804 Romero, P., Grego, E., Ariz, L., Figueroa, L., 2016. Contribución de las Áreas de Manejo de 805 recursos bentónicos al nivel socioeconómico de los pescadores artesanales de la macro zona centro sur de Chile, Sudamérica, Ciencia y Mar 13.

807 Rosas, J., Dresdner, J., Chávez, C., Quiroga, M., 2014. Effect of social networks on the 808

Ruano-Chamorro, C., Subida, M.D., Fernández, M., 2017. Fishers’ perception: An alternative source of information to assess the data-poor benthic small-scale artisanal fisheries of central Chile. Ocean Coast Manage 146, 67-76. https://doi.org/10.1016/j.ocecoaman.2017.06.007

San Martín, G., Parma, A.M., Orensanz, J.L., 2010. The Chilean experience with territorial use rights in fisheries. Handbook of marine fisheries conservation and management 24, 324-

818 Šidák, Z., 1967. Rectangular Confidence Regions for the Means of Multivariate Normal 819 Distributions. J Am Stat Assoc 62, 626-633. https://doi.org/10.1080/01621459.1967.10482935 (Pairwise Contrasts) for Arbitrary Sample Sizes. Technometrics 18, 89-97. https://doi.org/10.2307/1267921

827 Wilen, J.E., Cancino, J., Uchida, H., 2012. The Economics of Territorial Use Rights Fisheries, or 828

Zou, H., Hastie, T., 2005. Regularization and variable selection via the elastic net. J Roy Stat Soc B 67, 301-320. https://doi.org/10.1111/j.1467-9868.2005.00503.x 
831 Zúñiga, S., Ramírez, P., Valdebenito, M., 2008. Situación socioeconómica de las áreas de 832 manejo en la región de Coquimbo, Chile. Lat am jaquat res 36, 63-81.

833 https://doi.org/10.4067/S0718-560X2008000100005

834 Subpesca, 2003. is an Administrative document and should be: Documento de Difusión No. 1. 835 Áreas de Manejo y Explotación de Recursos Bentónicos. Departamento de Coordinación 836 Pesquera y Departamento de Pesquerías de la Subsecretaría de Pesca. Available at: 837 http://www.subpesca.cl/publicaciones/606/articles-9758_documento.pdf.

838

839 Tables

840 
841 Table 1. Response variable and predictor abbreviations and definitions for the elastic net model.

Variable Definition

\begin{tabular}{|c|c|}
\hline $\mathrm{Y}$ & Log-transformed, centered catches for species s in OAA areas per fishing cove (mt) \\
\hline Age_TURF_mean & Average time since the different TURFs implementation per fishing cove (yr) \\
\hline Age_TURF_max & Maximum time since the oldest TURF implemented per fishing cove (yr) \\
\hline Age_Organization_mean & Average time since the different fishers' organizations implementation per fishing cove (yr) \\
\hline Age_Organization_max & Maximum time since the oldest fishers' organization implemented per fishing cove (yr) \\
\hline N_TURF & Number of TURFs per fishing cove \\
\hline N_ORG & Number of fishers' organizations per fishing cove \\
\hline Area_OAA & Open access areas per fishing cove $\left(\mathrm{km}^{2}\right)$ \\
\hline Area_OAA ${ }^{2}$ & Open access areas per fishing cove $\left(\mathrm{km}^{4}\right)$ \\
\hline Area_Fraction & TURF areas divided by total fishing ground (TURF areas + OAA areas) (\%) \\
\hline Harvesters_All & Outside effort, or all licensed divers (or collectors) per fishing cove (divers or collectors) \\
\hline Harvesters_per_OAA & Outside effort divided by the OAA areas per fishing cove $\left(\mathrm{km}^{-2}\right)$ \\
\hline Harvesters_per_TURF & Inside effort divided by the TURF areas per fishing cove $\left(\mathrm{km}^{-2}\right)$ \\
\hline Limpet_per_diver & Catches of limpet inside TURF divided by inside effort (mt /diver) \\
\hline Kelp_per_collector & Catches of kelp inside TURF divided by inside effort (mt /diver) \\
\hline Urchin_per_diver & Catches of sea urchin inside TURF divided by inside effort (mt /diver) \\
\hline Loco_per_diver & Catches of loco inside TURF divided by inside effort (mt /collector) \\
\hline Coastline_length & Length of coast adjacent to the fishing cove $(\mathrm{km})$ \\
\hline Landings_port & Total landings (algae, fish, mollusk, crustacean, other) of fishing port(s) within $50 \mathrm{~km}$, if any (mt) \\
\hline Urban_area & Fishing cove is within $50 \mathrm{~km}$ to one of the ten biggest cities ${ }^{\text {a }}(1 \mid 0)$ \\
\hline
\end{tabular}

a Antofogasta, Arica, Conception, Iquique, Puerto Montt, Punta Arenas, San Antonio, Serena, Valdivia, Valparaiso. 
843 Table 2. Average size of TURFs and OAAs with associated average harvesters effort for fishing 844 coves considered in each region. Standard deviations are indicated in parentheses. Northern 845 regions consist of regions II, III, IV, V while southern regions include regions VIII, IX, XIV, X 846 and XI. The number of fishing coves included for each region is given by $\mathrm{N}$.

\begin{tabular}{llllll}
\hline & \multicolumn{2}{c}{ TURF } & & \multicolumn{2}{l}{ OPEN-ACCESS AREA } \\
\cline { 2 - 3 } \cline { 5 - 6 } Region & Area $\left(\mathrm{km}^{2}\right)$ & Effort (individual) & & Area $\left(\mathrm{km}^{2}\right)$ & Effort (individual) \\
\cline { 1 - 2 } Northern $N=63$ & $3.2( \pm 3.1)$ & $25.1( \pm 25.4)$ & & $60.8( \pm 16.5)$ & $33.1( \pm 34.5)$ \\
Southern $N=114$ & $4.9( \pm 9.3)$ & $37.0( \pm 57.1)$ & & $90.5( \pm 29.2)$ & $58.0( \pm 103.0)$ \\
\hline
\end{tabular}

849 Table 3. 2015 median catch rates (i.e., catch per unit of effort and catch per unit of area) from 850 inside TURFs and OAAs (i.e., outside TURFs) for each of the four species groups. CPUE is 851 given in $\mathrm{mt} / \mathrm{month} /$ harvester. CPUA is given in $\mathrm{mt} / \mathrm{month} / \mathrm{km}^{2}$. \% Diff. is the percentage 852 difference between median catch rates from the two areas.

\begin{tabular}{|c|c|c|c|c|c|c|c|c|c|c|}
\hline & Loco & Limpet & & & Kelp & & & Sea urc & chin & \\
\hline & Inside & Inside & Outside & \% Diff. & Inside & Outside & \% Diff. & Inside & Outsi & \% Diff. \\
\hline$\overline{\text { CPUE }}$ & 0.13 & 0.04 & 0.01 & 75.00 & 0.66 & 0.16 & 75.75 & 0.07 & 0.01 & 85.71 \\
\hline CPUA & 1.09 & 0.36 & 0.001 & 99.72 & 12.85 & 0.39 & 96.96 & 0.49 & 0.01 & 97.96 \\
\hline
\end{tabular}


854 Table 4. Results of the linear mixed effect models estimating log-transformed CPUAs for loco,

855 limpet, kelp, and sea urchin inside TURFs. Model 2 only considers a subsample of fishing coves

856 that have a constant number of TURF(s) for at least ten years. Significance is denoted by:

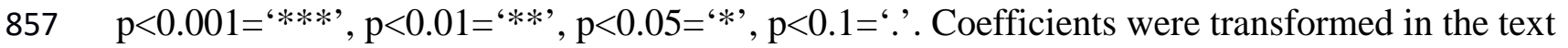

858 into percent changes in CPUA for a given change in the predictor variable using the following

859 formula: $\% \Delta y=100 \cdot\left(e^{\beta \Delta x}-1\right)$. Marginal and conditional coefficients of determination are

860 respectively given by $\mathrm{r}_{\mathrm{m}}^{2}$ and $\mathrm{r}_{\mathrm{c}}^{2}$. Number of observations and number of fishing coves included

861 for each model are respectively given by $\mathrm{n}$ and $\mathrm{N}$.

\begin{tabular}{|c|c|c|c|c|c|c|c|c|c|}
\hline \multirow[b]{2}{*}{ Model } & \multirow[b]{2}{*}{ Predictor } & \multicolumn{2}{|l|}{ Loco } & \multicolumn{2}{|l|}{ Limpet } & \multicolumn{2}{|l|}{ Kelp } & \multicolumn{2}{|c|}{ Sea urchin } \\
\hline & & Coeff. & p-value & Coeff. & p-value & Coeff. & p-value & Coeff. & p-value \\
\hline \multirow[t]{7}{*}{1} & Intercept & 1.19 & $1.23 \mathrm{E}-19 * * *$ & 0.37 & $0.01 *$ & 3.63 & $5.32 \mathrm{E}-18 * * *$ & 0.82 & $0.01 *$ \\
\hline & Year & -0.08 & $3.46 \mathrm{E}-25 * * *$ & -0.04 & $2.80 \mathrm{E}-4 * * *$ & -0.02 & 0.45 & -0.05 & $0.03 *$ \\
\hline & $\mathrm{N}_{\text {TURF }}$ & -0.11 & $1.19 \mathrm{E}-4 * * *$ & -0.29 & 3.07E-10 *** & -0.34 & $4.31 \mathrm{E}-7 * * *$ & -0.22 & $\begin{array}{c}4.10 \mathrm{E}-3 \\
* *\end{array}$ \\
\hline & $r_{m}^{2}$ & 0.10 & & 0.22 & & 0.25 & & 0.12 & \\
\hline & $r_{c}^{2}$ & 0.68 & & 0.64 & & 0.65 & & 0.72 & \\
\hline & $n$ & 1,077 & & 473 & & 203 & & 220 & \\
\hline & $N$ & 138 & & 78 & & 49 & & 50 & \\
\hline \multirow[t]{6}{*}{2} & Intercept & 178.18 & $2.47 \mathrm{E}-13 * * *$ & 21.22 & 0.49 & 138.30 & 0.16 & 53.13 & 0.53 \\
\hline & Year & -0.09 & $2.71 \mathrm{E}-13 * * *$ & -0.01 & 0.49 & -0.07 & 0.17 & -0.03 & 0.53 \\
\hline & $r_{m}^{2}$ & 0.08 & & $1.38 E-3$ & & 0.03 & & $2.81 E-3$ & \\
\hline & $r_{c}^{2}$ & 0.59 & & 0.63 & & 0.43 & & 0.67 & \\
\hline & $n$ & 372 & & 160 & & 52 & & 65 & \\
\hline & $N$ & 49 & & 31 & & 13 & & 16 & \\
\hline
\end{tabular}


863 Table 5. Results of the linear mixed effect models estimating log-transformed CPUAs for limpet,

864 kelp, and sea urchin outside TURFs (OAAs). There is no result for loco as it is not exploited in

865 OAAs. Model 2 only considers a subsample of fishing coves that have a constant number of

866 TURF(s) for at least ten years. Significance is denoted by: $\mathrm{p}<0.001=^{` * * *}, \mathrm{p}<0.01=^{` * *}$,

$867 \mathrm{p}<0.05={ }^{‘ *}, \mathrm{p}<0.1=^{`} . \therefore$ Coefficients were transformed in the text into percent changes in CPUA

868 for a given change in the predictor variable using the following formula: $\% \Delta y=100$.

$869\left(e^{\beta \Delta x}-1\right)$. Marginal and conditional coefficients of determination are respectively given by $\mathrm{r}_{\mathrm{m}}^{2}$

870 and $r_{c}^{2}$. Number of observations and number of fishing coves included for each model are

871 respectively given by $\mathrm{n}$ and $\mathrm{N}$.

\begin{tabular}{|c|c|c|c|c|c|c|c|}
\hline \multirow[b]{2}{*}{ Model } & \multirow[b]{2}{*}{ Predictor } & \multicolumn{2}{|l|}{ Limpet } & \multicolumn{2}{|l|}{ Kelp } & \multicolumn{2}{|c|}{ Sea urchin } \\
\hline & & Coeff. & p-value & Coeff. & p-value & Coeff. & $\mathrm{p}$-value \\
\hline \multirow[t]{7}{*}{1} & Intercept & -5.87 & $1.40 \mathrm{E}-16 * * *$ & -2.63 & 8.03E-19*** & -5.23 & $2.48 \mathrm{E}-16 * * *$ \\
\hline & Year & -0.05 & 4.57E-9 $* * *$ & 0.03 & $0.03 *$ & $-8.01 \mathrm{E}-3$ & 0.41 \\
\hline & $\mathrm{N}_{\text {TURF }}$ & 0.02 & 0.61 & -0.03 & 0.66 & $6.87 \mathrm{E}-3$ & 0.85 \\
\hline & $r_{m}^{2}$ & 0.01 & & $2.21 E-3$ & & $2.33 E-4$ & \\
\hline & $r_{c}^{2}$ & 0.60 & & 0.81 & & 0.75 & \\
\hline & $n$ & 1,433 & & 933 & & 1,155 & \\
\hline & $N$ & 179 & & 148 & & 161 & \\
\hline \multirow[t]{6}{*}{2} & Intercept & 44.93 & $0.05^{*}$ & 4.49 & 0.92 & -23.49 & 0.45 \\
\hline & Year & -0.03 & $0.02 *$ & $-3.01 E-3$ & 0.89 & $8.82 \mathrm{E}-3$ & 0.57 \\
\hline & $r_{m}^{2}$ & $4.84 E-3$ & & $2.59 E-5$ & & $3.29 E-4$ & \\
\hline & $r_{c}^{2}$ & 0.55 & & 0.65 & & 0.66 & \\
\hline & $n$ & 534 & & 336 & & 394 & \\
\hline & $N$ & 54 & & 49 & & 52 & \\
\hline
\end{tabular}

872 
873 Table 6. Change in OLS variance explained with specific variables: OLS_all includes all initial

874 predictors, OLS_TURF includes only TURF related predictors, OLS_Geo includes only

875 geospatial context predictors and OLS_elastic includes only predictors selected by the elastic net

876 model.

\begin{tabular}{llllll}
\hline & & OLS_all & OLS_TURF & OLS_Geo & OLS_elastic \\
\hline \multirow{2}{*}{ Limpet } & Adj.r $r^{2}$ & 0.31 & 0.12 & 0.25 & 0.31 \\
& $\mathrm{r}^{2}$ & 0.54 & 0.28 & 0.37 & 0.36 \\
\hline \multirow{2}{*}{ Kelp } & Adj.r & 0.55 & 0.26 & 0.42 & 0.55 \\
& $\mathrm{r}^{2}$ & 0.71 & 0.40 & 0.52 & 0.65 \\
\hline \multirow{2}{*}{ Sea Urchin } & Adj.r & 0.34 & 0.33 & 0.40 & 0.51 \\
& $\mathrm{r}^{2}$ & 0.70 & 0.52 & 0.55 & 0.58 \\
\hline
\end{tabular}

877 
878 Table 7. Results of the elastic net regression model estimating catches for limpet, sea urchin and

879 kelp outside the TURFs according to $\lambda_{\min }$, the value that minimizes the cross-validation MSE

880 which yields the most accurate model. Only predictors that were selected for at least $40 \%$ of the

881 10,000 bootstraps are shown in this table and they are ranked according to their importance (i.e.,

882 higher percentage of inclusion in the model). Elastic net mean coefficients were returned on the

883 original scale here but they were transformed in the text into percent changes in catch for a given

884 change in the predictor variable using the following formula: $\% \Delta y=100 \cdot\left(e^{\beta \Delta x}-1\right)$. OLS

885 normalized coefficients are unitless. Number of observations for each model is given with n.

\begin{tabular}{|c|c|c|c|c|c|}
\hline & Predictor & $\%$ inclusion & Sign & $\begin{array}{l}\text { Elastic net } \\
\text { coefficient } \\
\end{array}$ & $\begin{array}{l}\text { OLS normalized } \\
\text { coefficient }\end{array}$ \\
\hline Limpet & Divers_All a & 100 & + & 0.02 & 0.99 \\
\hline \multirow[t]{3}{*}{$n=54$} & Urban_Area & 83.69 & - & 0.40 & 0.50 \\
\hline & Area_OAA ${ }^{2}$ & 60.35 & - & $8.15 \mathrm{E}-5$ & 0.58 \\
\hline & Area_fraction & 41.86 & - & 0.02 & 0.72 \\
\hline Kelp & Collectors_All a & 100 & + & $2.31 \mathrm{E}-3$ & 0.93 \\
\hline \multirow[t]{10}{*}{$n=54$} & Urban_Area & 99.73 & - & 1.28 & 0.63 \\
\hline & Loco_per_diver & 91.11 & + & 0.35 & 0.47 \\
\hline & Area_OAA & 90.48 & - & 0.01 & 0.51 \\
\hline & Area_OAA $^{2}$ & 84.77 & - & $1.03 \mathrm{E}-4$ & $2.10 \mathrm{E}-3$ \\
\hline & Age_TURF_max & 84.40 & - & 0.08 & 0.16 \\
\hline & Kelp_per_collector & 78 & + & 0.01 & 0.29 \\
\hline & Age_TURF & 73.03 & - & 0.05 & 0.33 \\
\hline & Age_Organization_max & 59.74 & - & 0.07 & 0.16 \\
\hline & Area_fraction & 47.36 & - & 7.53E-3 & 0.18 \\
\hline & N_ORG & 41.80 & - & 0.05 & 0.48 \\
\hline Sea & Divers_All ${ }^{\mathrm{a}}$ & 100 & + & 0.01 & 1.37 \\
\hline Urchin & Coastline_length & 99.67 & + & 0.01 & 1.86 \\
\hline
\end{tabular}




\begin{tabular}{llllll}
$n=36$ & Limpet_per_diver & 62.45 & - & $4.84^{\mathrm{b}}$ & 0.48 \\
& Age_TURF_max & 47.34 & - & 0.04 & 0.56 \\
& Age_TURF & 46.96 & - & 0.03 & 0.02 \\
\hline
\end{tabular}

886

887 a The shrinkage penalty was set to 0 for the variable Divers_All and Collectors_All (instead of 1

888 for other variables), forcing this variable to be included in the model.

889 b This large effect is driven by two outliers. Removing this predictor did not change qualitatively 890 the results.

891

$892 \quad$ Figures 


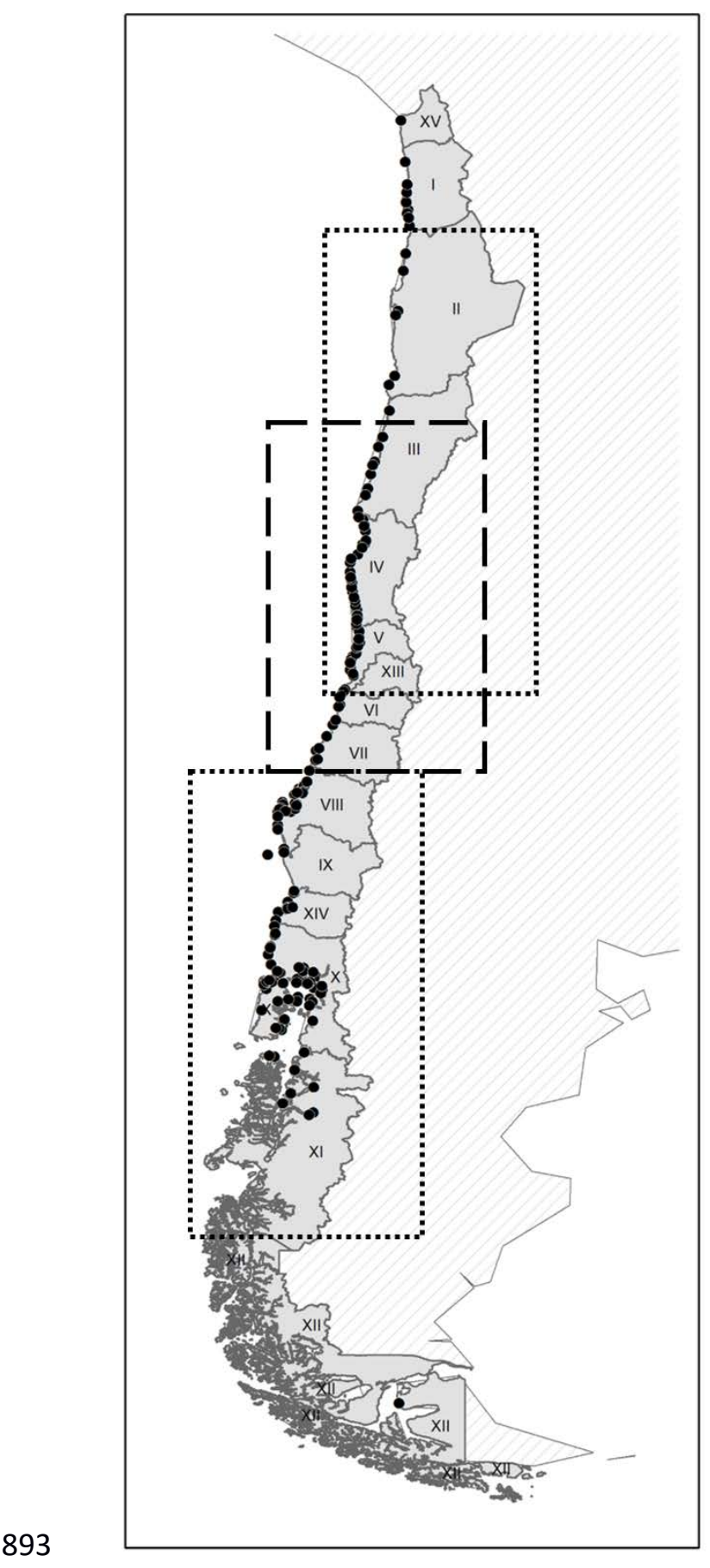

894 Figure 1. Administrative regions of Chile. Fishing coves included in the comparison of 2015 catch 895 rates and mixed effect models are represented with the black dots. The elastic net regressions only 896 consider fishing coves within the northern regions II, III, IV, V and within the southern regions 
897 VIII, IX, XIV, X and XI (dotted rectangles). The $20 \mathrm{~m}$ isobaths layer was only available from 898 central Chile (dashed rectangle from $27^{\circ}$ to $36^{\circ}$ ).

899 

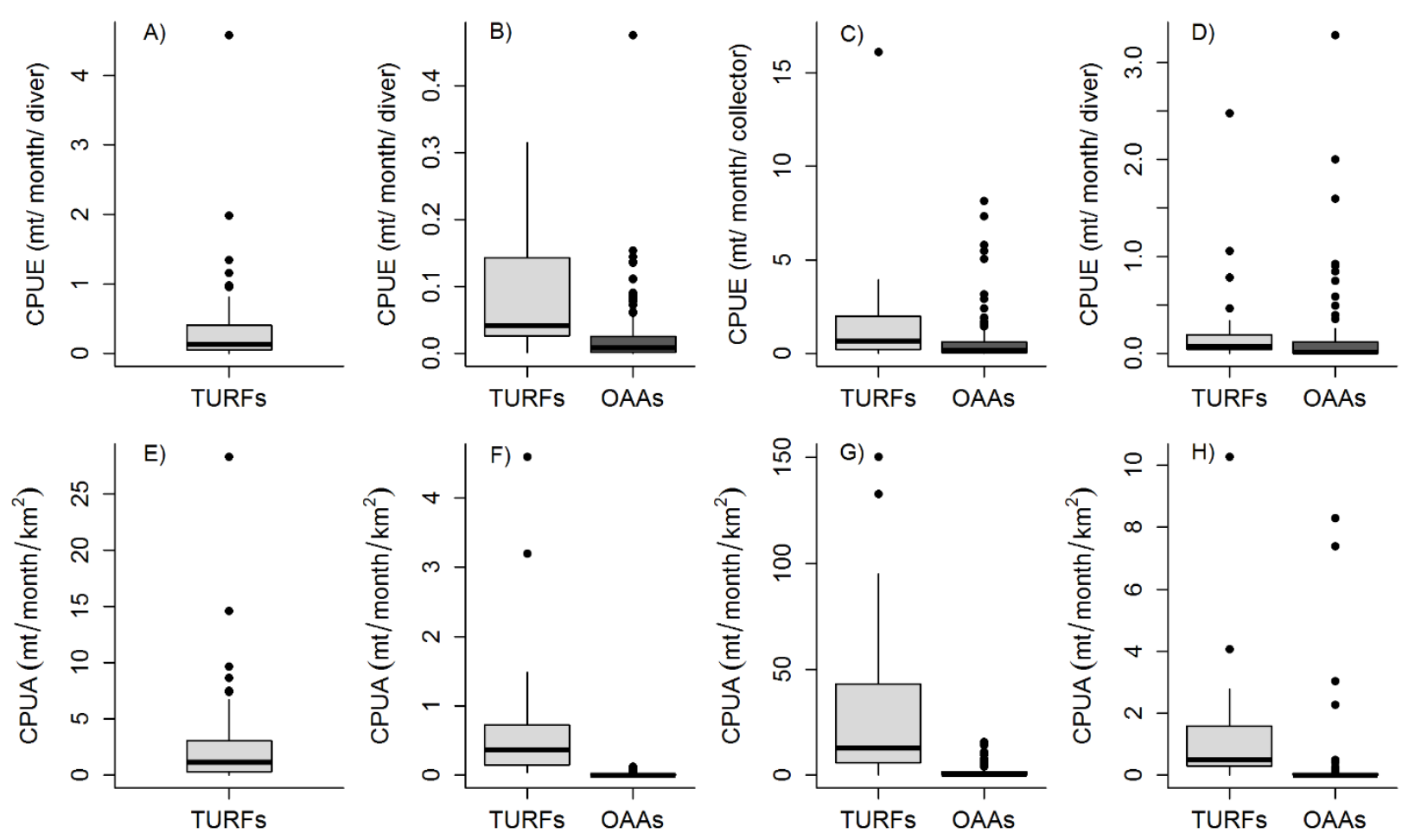

901 Figure 2. Boxplots of 2015 CPUEs (A, B, C, D) and CPUAs (E, F, G, H) for the four species loco 902 (A,E) keyhole limpet (B, F), kelp (C, G), and red sea urchin (D, H) by fishing coves, differentiated 903 by catch origin inside or outside TURFs (i.e. OAA). Loco's extraction is banned in OAAs. 

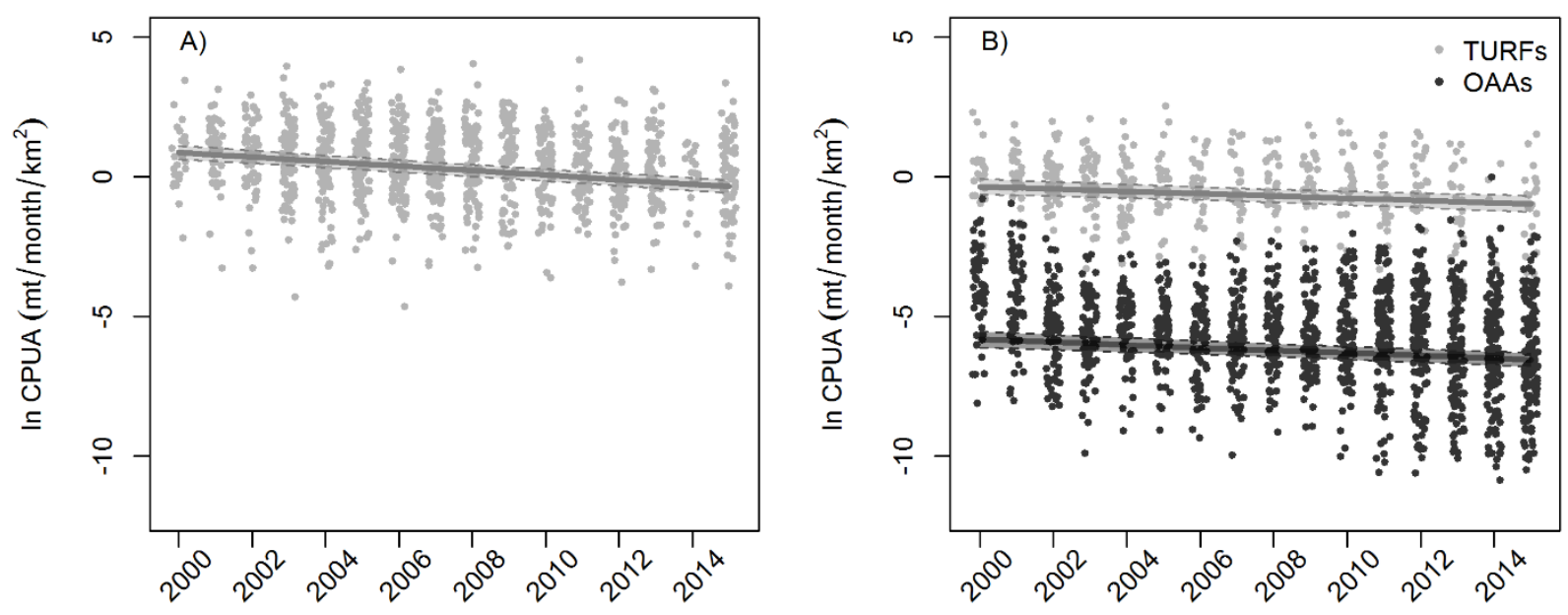

905
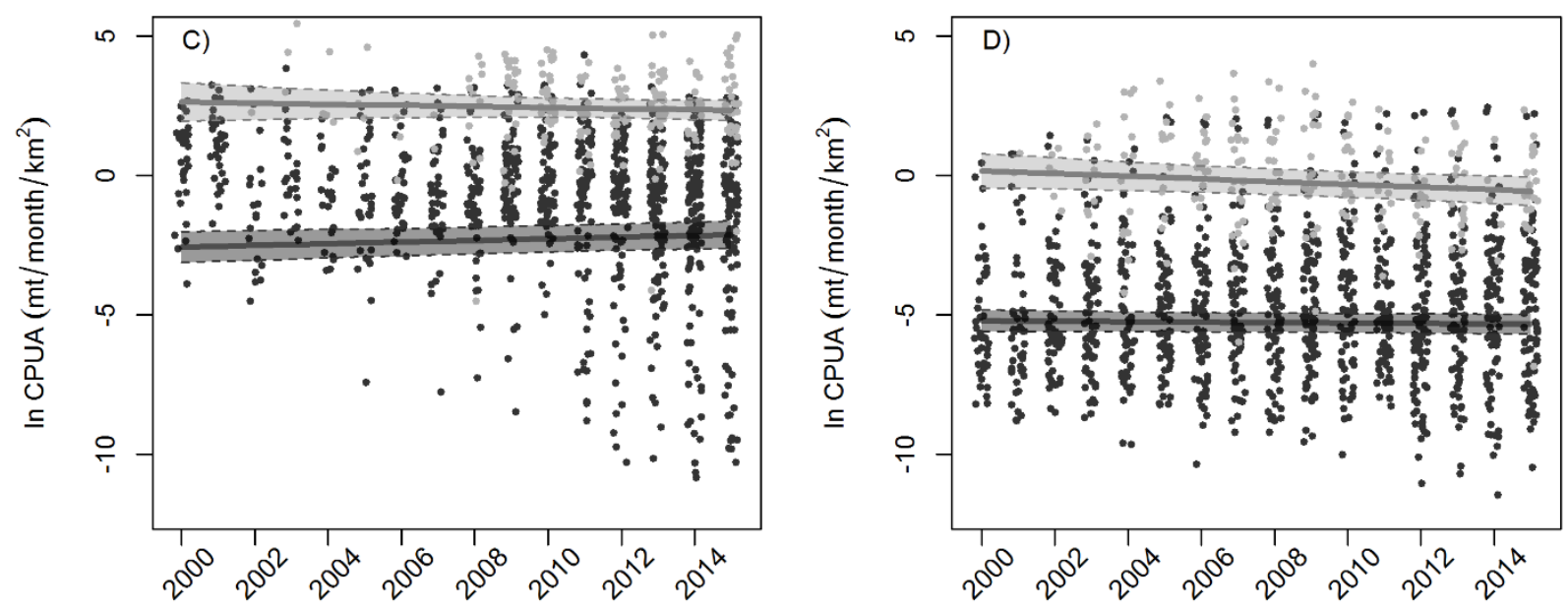

906 Figure 3. Observed catch per unit of area (mt/ month/ $\mathrm{km}^{2}$ ) values for the four species loco (A),

907 keyhole limpet (B), kelp (C), and red sea urchin (D) used in the mixed effect models. Light grey 908 dots are CPUAs from inside TURFs, dark grey dots are CPUAs from OAAs. Predicted value and 909 standard errors for a given year is given by the straight line and shaded area. 
Appendices 
A1. TURFs status in Chile in 2017.

\begin{tabular}{llc}
\hline TURF status Definition & Count
\end{tabular}

\section{Designated} with a public decree in force

Assigned to a fisher
organization (ecree in force

TURF status

Definition

$\mathrm{Oper}$
study, an approved management plan, a use agreement and a TAC in place.

In stand-by TURF for which monitoring has not been conducted by the due date. However, there was a quota assigned in the last 4 years.

Rejected

TURFs without an assigned fishing association 4 (include a change in organizations and rejected application).

Available for assignment

Disaffected

In evaluation

Designated TURFs that are not assigned to a fishing 164 organization yet or the organization has not complied with necessary initial baseline studies.

391 
A)

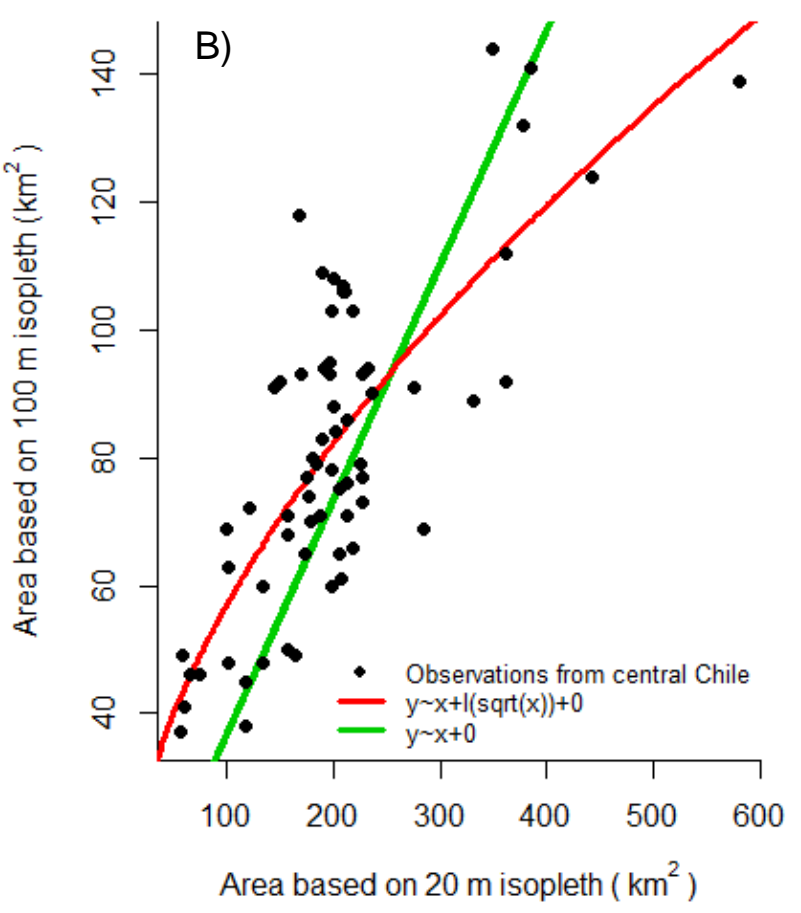

A2. A) Total fishing grounds (comprising TURFs and OAAs) were created per fishing cove based on sailing time and bathymetry. The offshore width of these polygons was based on a typical maximum harvest depth of $20 \mathrm{~m}$ (dashed line) extrapolated for the whole coast from a $100 \mathrm{~m}$ isobaths layer (dotted line, source GEBCO). Estimates of OAA areas were calculated as fishing ground areas minus assigned TURFs areas (grey striped area). B) Fishing ground area based on bathymetry $20 \mathrm{~m}$ in function of fishing ground area based on bathymetry $100 \mathrm{~m}$ according to the relationship $\mathrm{y}=\mathrm{x}+\sqrt{?}$ ? +0 (red line) that fits better than the relationship $\mathrm{y}=\mathrm{x}+0$ (green line). 
A)

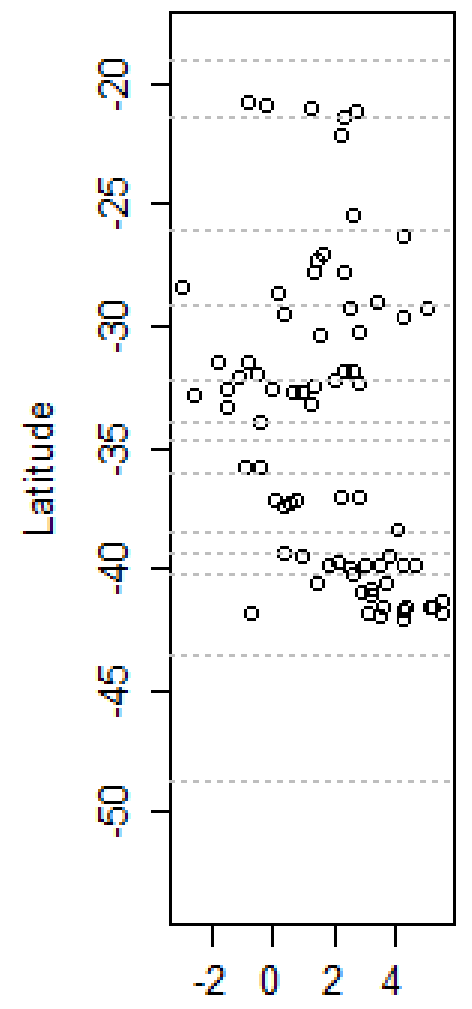

Log catches (mt)
B)

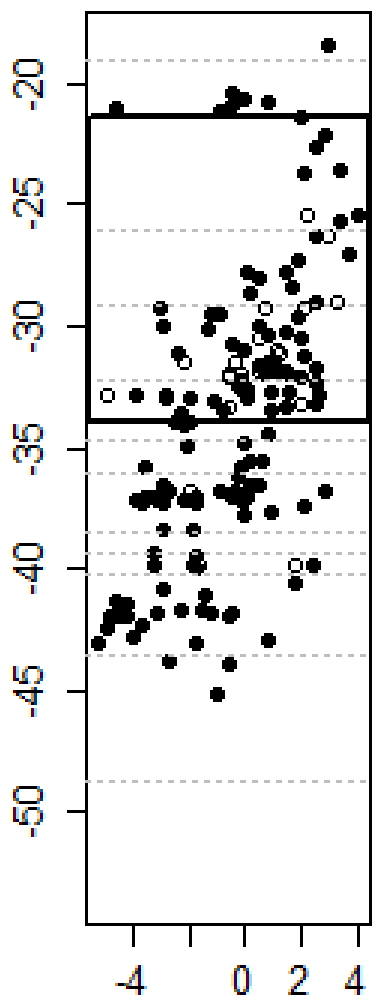

Log catches (mt)
C)

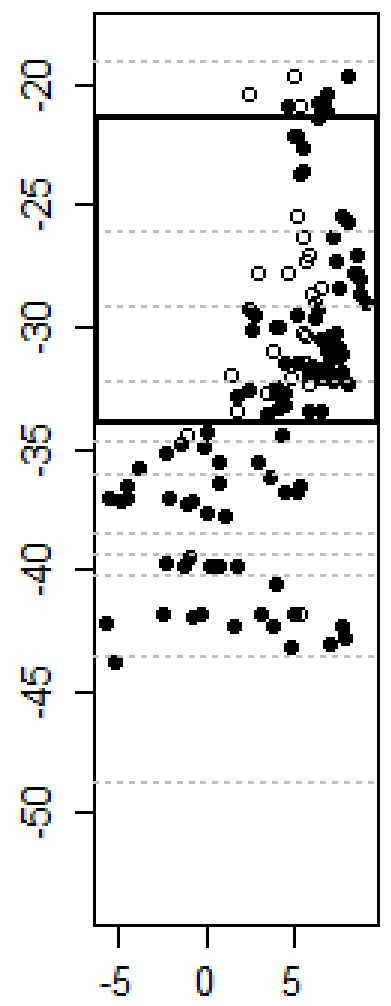

Log catches (mt)
D)

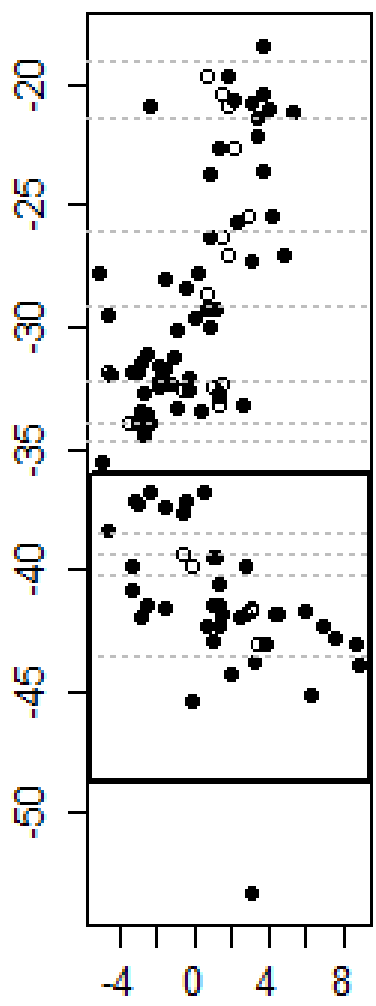

Log catches (mt)

- Catch TURF • Catch OAA

Administrative regions - Regional grouping

A3. Log catches (mt) per fishing coves as a function of latitude for each group of species: loco (A), keyhole limpet (B), kelp (C), and red sea urchin (D) and differentiated by their origin, i.e., catches inside TURFs (white dots) or from the OAA (black dots). Dashed lines represent the delimitations of the 15 administrative regions of Chile. Black boxes represent regional grouping of important regions for each fishery. 
A4. Elastic net model development

Given a linear regression model with p predictors, the elastic net solves this regularization problem:

Where

$$
\min _{\beta_{0}, \beta}\left(\frac{1}{2 N_{s}} \sum_{i=1}^{N_{s}}\left(y_{i, s}-\beta_{0, s}-x_{i, s}^{T} \beta_{p, s}\right)^{2}+\lambda P_{\alpha}\left(\beta_{p, s}\right)\right),
$$

$$
P_{\alpha}\left(\beta_{p, s}\right)=\frac{(1-\alpha)}{2}\left\|\beta_{p, s}\right\|_{2}^{2}+\alpha\left\|\beta_{p, s}\right\|_{1}=\sum_{j=1}^{p}\left(\frac{(1-\alpha)}{2} \beta_{j}^{2}+\alpha\left|\beta_{j}\right|\right) .
$$

In (1), $y_{i, s}$ is the response, here catches of species $s$ in the open access area at fishing cove $i$; $N_{s}$ is the number of fishing coves with catches from OAAs for species $s ; x_{i, s}$ is explanatory data, a vector of $p$ values for species $s$ at fishing cove $i ; \beta_{p, s}$ is the for species $s ; \lambda$ is a positive regularization parameter; and $\alpha$ is the elastic net penalty. The coefficient for each $p$ predictor elastic net minimizes the sum of squared differences between observed and predicted values subject to a constraint, $P_{\alpha}(\beta)$, that penalizes for model complexity as well as for large absolute values of normalized coefficients (Equations 1, 2). The form of the penalty is controlled by the parameter $\alpha$. With $\alpha=0$, coefficients of correlated predictors shrink towards each other. With $\alpha=1$, the most influential correlated predictor is selected while others are discarded. The elastic net sets $\alpha$ to 0.5 , which leads to selection of groups of predictors that independently or jointly explain variance (Equation 2, Zou and Hastie 2005, Friedman et al. 2010). Separate penalty factors can be applied to each coefficient to allow different shrinkage. In our case, the penalty factors were considered equal for all variables except for the variable Harvesters_all (representing the total number of harvesters), for which the penalty was set to 0 so that this variable was always included in the model. The optimal value of the regularization parameter $\lambda$, which controlled the strength of the penalty, was selected using a 10-fold cross-validation method. Two different values of $\lambda$ were considered: the value that minimized the cross-validation mean squared error (MSE) $\left(\lambda_{\min }\right)$, and the maximum value within one standard error of the $\lambda_{\min }\left(\lambda_{1 \mathrm{SE}}\right)$. The more restrictive regularization with $\lambda_{1 \mathrm{SE}}$ (i.e., the larger penalty that leads to models with smaller or fewer parameter values) yields a simpler model while maintaining a level of accuracy found to be close to that obtained when using $\lambda_{\min }$ (Hastie et al. 2009). The cross-validation process, which randomly selects training data and returns new values for $\lambda_{1 \mathrm{SE}}$ and $\lambda_{\min }$ at each iteration, was repeated 1,000 times and the final model used average values for $\lambda_{1 \mathrm{SE}}$ and $\lambda_{\min }$. 
A5. Elastic net model results with $\lambda_{1 \mathrm{SE}}$

Results of the elastic net regression model estimating catches for limpet, sea urchin and kelp outside the TURFs according to $\lambda_{1 \mathrm{SE}}$, the maximum value within one standard error of the $\lambda_{\text {min }}$ which yields the most restrictive model. Only predictors that were selected for at least $40 \%$ of the 10,000 bootstraps are shown in this table and they are ranked according to their importance (i.e., higher percentage of inclusion in the model). Elastic net mean coefficients were returned on the original scale here but were transformed in the text into percent changes in catch for a given change in the predictor variable using the following formula: $\% \Delta ? ?=100 \cdot\left(? ?^{? ? \Delta ? ?}-1\right)$. OLS normalized coefficients are unitless.

\begin{tabular}{llccll}
\hline & Non-null predictor & \% inclusion & Sign & $\begin{array}{l}\text { Elastic net } \\
\text { coefficient }\end{array}$ & $\begin{array}{l}\text { OLS normalized } \\
\text { coefficient }\end{array}$ \\
\hline Limpet & Divers_All a & 100 & + & 0.021 & 0.661 \\
& Urban_Area & 41.43 & - & 0.100 & 0.644 \\
\hline Kelp & Collectors_All a & 100 & + & 0.002 & 0.448 \\
& Urban_Area & 99.49 & - & 0.976 & 0.860 \\
& Area_OAA & 86.25 & - & 0.006 & 0.435 \\
& Area_OAA & 85.89 & - & $7.68 \mathrm{E}-5$ & 0.025 \\
& Age_TURF_mean & 67.20 & - & 0.031 & 0.181 \\
& Age_TURF_max & 51.78 & - & 0.025 & 0.324 \\
\hline Sea & Divers_All a & 100 & + & 0.011 & 1.231 \\
Urchin & Coastline_length & 98.98 & + & 0.006 & 2.087 \\
\hline
\end{tabular}

a The shrinkage penalty was set to 0 for the variable Divers_All and Collectors_All (instead of 1 for other variables), forcing this variable to be included in the model. 
A5. Elastic net model results with $\lambda_{1 \mathrm{SE}}$

For the most restrictive models using the regularization parameter $\lambda_{1 \mathrm{SE}}$, most of the predictors retained to explain catch in OAAs were related to the geospatial context. The predictor Urban_Area was selected in $41.30 \%$ of the 10,000 bootstraps when modeling limpet catches and $99.49 \%$ of the bootstraps when modeling kelp extraction, being the strongest identified driver of catch outside of TURFs in both cases. This predictor exhibited a negative relationship with catches outside TURFs for both species groups, with lower catches in OAAs for limpet (10\% decrease) and kelp (165\% decrease) close to urban areas.

No other predictors were selected for limpet, whereas several predictors related to OAA and time since TURF implementation were selected for kelp. Lower catches of kelp outside of TURFs were counterintuitively associated with fishing coves that had larger OAA areas (6\% decrease in catch for every additional $10 \mathrm{~km}^{2}$ of OAA area). Area_OAA and Area_OAA ${ }^{2}$ were selected in at least $80 \%$ of bootstraps and were considered to be highly important drivers for kelp catch outside of TURFs. Moderately lower catches of kelp outside of TURFs (3\% decrease) were associated with fishing coves that had older TURFs. The related variables Age_TURF_mean and Age_TURF_max were included in $67.2 \%$ and $51.78 \%$ of the bootstraps, respectively.

Higher catches of sea urchin in OAAs were associated with fishing coves that have longer coastline lengths (6\% increase in catch for every additional $10 \mathrm{~km}$ of coastline). This predictor was the only additional factor selected for explaining sea urchin catches in OAAs (selected in $98.98 \%$ of cases). 

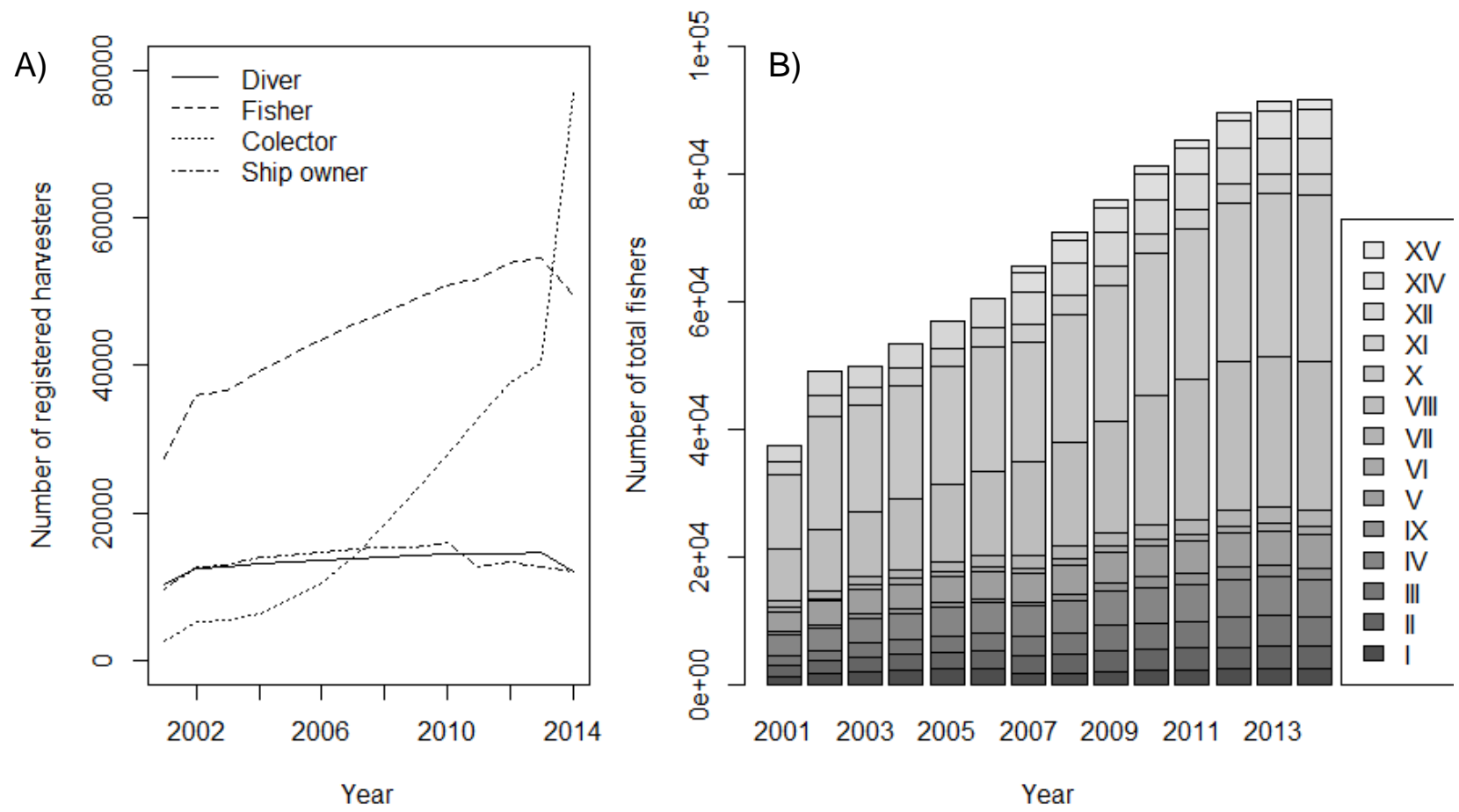

A6. A) Number of active licensed harvesters over time according to the different categories with the solid line representing number of divers for loco, limpet and sea urchin exploitation and the dotted line representing the number of collectors mainly for kelp extraction. The different categories are not mutually exclusive. Licensed harvesters can exploit the open-access area but are not necessarily granted TURF access. B) Total number of licensed harvesters per regions and per year. 
A7. Test of heteroscedasticity using the Studentized Breusch-Pagan test from the OLS output considering all initial predictors. P-values $<0.05$ indicate heteroscedasticity of the OLS residuals.

\begin{tabular}{ll}
\hline Species & All predictors \\
\hline Limpet & $\mathrm{p}=0.35$ \\
Kelp & $\mathrm{p}=0.83$ \\
Sea urchin & $\mathrm{p}=0.97$ \\
\hline
\end{tabular}

